\title{
Article \\ Comparison of Support Effects on Phillips and Metallocene Catalysts
}

\author{
Qing Yang and Max Paul McDaniel *
}

check for updates

Citation: Yang, Q.; McDaniel, M.P. Comparison of Support Effects on Phillips and Metallocene Catalysts. Catalysts 2021, 11, 842. https:// doi.org/10.3390/catal11070842

Academic Editors:

Alessandro Piovano, Giorgia Zanchin and Silvia Bordiga

Received: 7 June 2021

Accepted: 8 July 2021

Published: 13 July 2021

Publisher's Note: MDPI stays neutral with regard to jurisdictional claims in published maps and institutional affiliations.

Copyright: (c) 2021 by the authors. Licensee MDPI, Basel, Switzerland. This article is an open access article distributed under the terms and conditions of the Creative Commons Attribution (CC BY) license (https:/ / creativecommons.org/licenses/by/ $4.0 /)$.
Chevron Phillips Chemical Co., Bartlesville, OK 74006, USA; YangQ@cpchem.com

* Correspondence: McDanMP@cpchem.com

\begin{abstract}
Both metallocene and Phillips chromium catalysts are used in the commercial manufacture of polyethylene. Unlike most other commercial metallocene systems, the Chevron Phillips Chemical (CPC) platform does not use methylaluminoxane or fluoroorganic boranes. Instead, the support itself serves to activate (ionize) the metallocenes, which then polymerize ethylene at high activity. Most of these solid acid supports can also be used to anchor $\mathrm{Cr}$ to make a Phillips catalyst. This provides an interesting opportunity to compare the polymerization responses by these two disparate systems, Phillips Cr and CPC metallocene, when supported on the same solid acid carriers. In this study, both chromium oxide and several metallocenes were deposited onto a variety of solid oxides, under a variety of conditions, and the resulting support effects were observed and compared. Although using seemingly different chemistries, the two catalyst systems exhibited a surprising number of similarities, which can be attributed to the acidity and porosity of these diverse supports.
\end{abstract}

Keywords: ethylene polymerization; Phillips catalyst; Cr/silica; solid acid; metallocene activation; long-chain branching

\section{Introduction}

Upon first reflection, one might not expect the chemistry of Phillips versus metallocene catalysts to have much in common. The former is entirely inorganic [1] whereas the latter is mostly, and often totally, composed of organometallic ingredients. However, both catalysts do polymerize ethylene to produce linear high molecular weight polymers, by a Cosseetype mechanism [2]. Both can also be supported on solid oxide carriers, with high porosity and sometimes high acidity $[3,4]$. In this paper we point out the often parallel, but also sometimes different, responses by the two catalysts to manipulation of those supports.

In its simplest form, the Phillips catalyst is made by depositing a chromium compound (usually trivalent) onto a support (usually silica) followed by calcination in dry oxygen. At about $400{ }^{\circ} \mathrm{C}$, the chromium is oxidized into the hexavalent form, which spreads out and becomes anchored onto the support as chromate or dichromate surface esters [3,5-14]. These species are then reduced by ethylene to a lower valence, expanding the potential coordination sphere, alkylating the $\mathrm{Cr}$, and forming the coordinatively unsaturated active sites [3-5,15-20]. Consequently, and somewhat unusually for inorganic industrial catalysts, the active sites are individually attached to the support. This provides the vehicle by which the support may have profound influences on the polymerization activity and the character of the resultant polymer. The process is illustrated in Scheme 1.

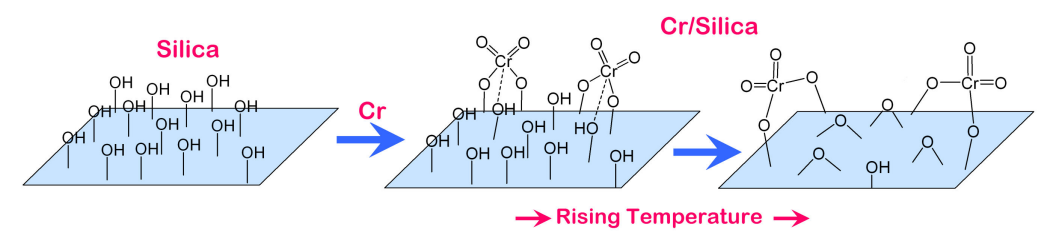

Scheme 1. Oxidation of the and subsequent anchoring to the support upon calcination. 
The activity of Phillips catalyst is enhanced as the calcination temperature is increased above $400{ }^{\circ} \mathrm{C}$, up to $900{ }^{\circ} \mathrm{C}$. The surface becomes increasingly dehydroxylated, which removes ligands and probably introduces more strain into the anchoring bonds as the silica surface anneals $[3,8,21-24]$. Due to this process, and because the surface is usually amorphous, variations appear in the reactivity of individual sites. Some sites tend to produce longer PE chains than other sites, and the net result is a broad molecular weight (MW) distribution, reflecting the $\mathrm{Cr}$ active site distribution. Consequently, the MW distribution can be quite sensitive to the choice of support and its thermal history $[3,9,21,25-31]$.

In contrast, the simplest metallocene catalysts are a combination of the alkylated metallocene and a Lewis acid. The latter is most commonly methylaluminoxane (MAO) [32,33] or sometimes fluoroorganic boranes such as tris(pentafluorophenyl) borane [34]. A support is not needed for activity, but silica is often used commercially with MAO [32,35,36]. MAO is a large polymeric molecule, especially after being dried, and therefore it becomes the actual support. Silica serves more as a template for the growth of polymer particles rather than a catalyst support in the usual sense. In fact, most of the MAO molecules are too large to penetrate the silica. Thus, interaction between the metallocene and the silica surface is minimal in such systems.

However, 25 years ago Chevron-Phillips Chemical (CPC) introduced another commercial family of metallocene activators. In this system, the Lewis acid is an acidic solid oxide support $[37,38]$. In addition, an aluminum alkyl, such as triethylaluminum, is added to alkylate the metallocene halide. This catalyst system is illustrated in Scheme 2, where the solid acid is considered the activating agent. In this system, there is definitely an interaction between acidic sites on the support and the metallocene. Without the support, the metallocene is not active.

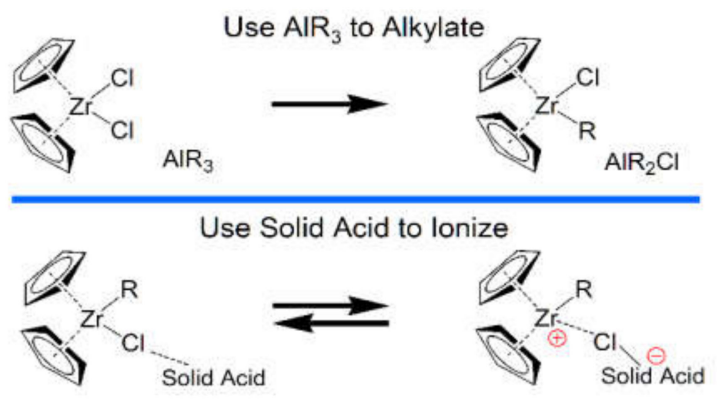

Scheme 2. Anchoring of the metallocene onto solid acids.

Nearly all of the acidic solid oxides used as activators in the CPC metallocene platform, can also be used to support a Phillips catalyst. Consequently, it is interesting to compare and contrast the various responses from both catalyst types when using a common support. This is the focus of the current report, in which the activity was monitored, as well as various polymer characteristics. Despite the seemingly different chemistries between the two catalyst types, many parallels were found, of which a few examples are described below.

\section{Results}

\subsection{The Influence of Active Metal Ligation on the Polymer from Both Catalysts}

\subsubsection{Shared Factors Influencing Comonomer Incorporation}

Most polyethylene produced commercially with Phillips [39-41] and metallocene catalysts [38] is actually a random copolymer of ethylene and 0.1 to $4 \mathrm{~mol} \%$ of an $\alpha$-olefin, typically 1-butene, 1-hexene or 1-octene. This adds branching to the otherwise linear chain backbone, which lowers crystallinity, thus enhancing polymer flexibility and toughness. However, due to their larger size, the $\alpha$-olefins are much less reactive than ethylene, and consequently the incorporation efficiency becomes an important commercial parameter for both types of catalyst. In the following examples polymers from both types of catalysts 
were analyzed by several techniques [42-45] which are described in the "Materials and Methods" section further below.

Metallocene catalysts become more efficient at incorporating $\alpha$-olefins when the rings of the metallocene are tied together by a tight bridge. This probably tends to pull the rings out of the metal orbitals, thus better exposing the metal and also increasing its positive charge or electron deficiency (Lewis acidity). This effect of the "bite angle" has been well-studied by numerous researchers [46-49]. In addition to the steric advantage, the charge effect may also favor $\alpha$-olefins because they are better electron donors than ethylene. The steric effect is usually considered to be the dominant one [46,47,50-53], although there are cases where the electronic effect also seems to play a role [3], for example in some comparisons where the bite angle is identical, but the charge is quite different. An example of the bridge effect was shown in an earlier report [54] in which the 1-hexene incorporation efficiency was measured on a series of bis-indenyl zirconium dichloride compounds as a function of the bridge length. The structures are illustrated in Scheme 3, consisting of one unbridged and four rac-bridged compounds. The comonomer incorporation efficiency increased by three-fold as the bridge became tighter, being varied (left to right) from no bridge to a $\mathrm{C} 4$ bridge, to a $\mathrm{C} 3$, then $\mathrm{C} 2$ and finally to a single-atom silicon bridge.
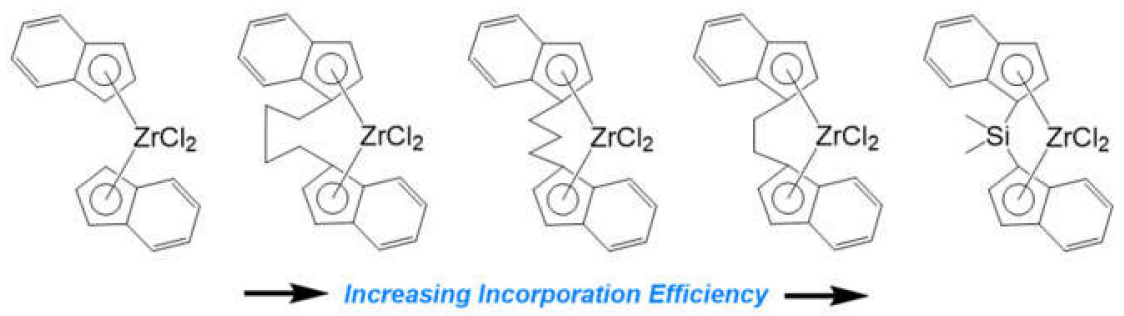

Scheme 3. $\alpha$-Olefin incorporation efficiency as a function of metallocene bridge size.

In what may be a parallel behavior, Phillips catalysts become more efficient at incorporating $\alpha$-olefins after high calcination temperatures [55]. It was noted in the Introduction section that calcination at high temperature removes ligands, which could improve steric access around the active sites. It probably also adds strain to the anchoring bonds as the silica surface anneals. Scheme 1 illustrates this by the stretching of the $-\mathrm{O}-\mathrm{Cr}-\mathrm{O}-$ bonds. Like the metallocene tight bridge, this may tend to pull the $\mathrm{Cr}$ out of the orbitals, increasing its electron deficiency and thus its reactivity with $\alpha$-olefins.

Phillips catalysts also tend to concentrate $\alpha$-olefin comonomer into the low-MW side of the MW distribution. Electron-donor poisons seem to affect these sites preferentially, which may also hint that these sites are more electron deficient [56,57]. In addition, they were found to be more easily reduced by $\mathrm{CO}$ and ethylene [56], again indicating higher reactivity. This latter point is further discussed below in connection with long chain branching.

\subsubsection{Shared Factors Influencing the Molecular Weight Distribution}

The molecular weight (MW) distributions from Phillips catalysts are usually broad, reflecting the wide variety of active site types that are always present on the surface. The polydispersity $\left(M_{W} / M_{N}\right)$ can vary from 4 to 100 depending on the support. This is because each site is individually attached to the support and has its own peculiar geometry and ligand field. In contrast, metallocenes supported on solid acids usually produce polymer with a polydispersity near 2.0, which is the value theoretically expected from a single non-living active site. In other words, all the active sites on the metallocene catalyst are nearly identical.

This is because the site environment, or coordination sphere of the metal, is largely determined by the organic metallocene structure, and especially the rings. The attachment to the surface is different from that of Phillips catalysts. Metallocene activation is usually considered to be partial or complete ionization by the removal of a halide or alkyl ligand [58-61]. Scheme $4 \mathrm{~A}$ illustrates the simplified mechanism in which a chloride is removed by a Lewis 
acidic surface site. Notice that in the process there is no direct attachment of the $\mathrm{Zr}$ to the support, only electrostatic attraction. The Zr coordination sphere does not contain a ligand from the support. This is different from Phillips catalysts, and helps to explain why metallocenes, even on solid acid supports, usually produce single site MW distributions. In commercial practice, supporting a metallocene on MAO or solid acid made very little difference, if any, in the polymer's molecular weight or MW distribution. This might imply that steric factors play a large role in determining the MW distribution from chromium catalysts too, although those surface factors are still largely unknown.

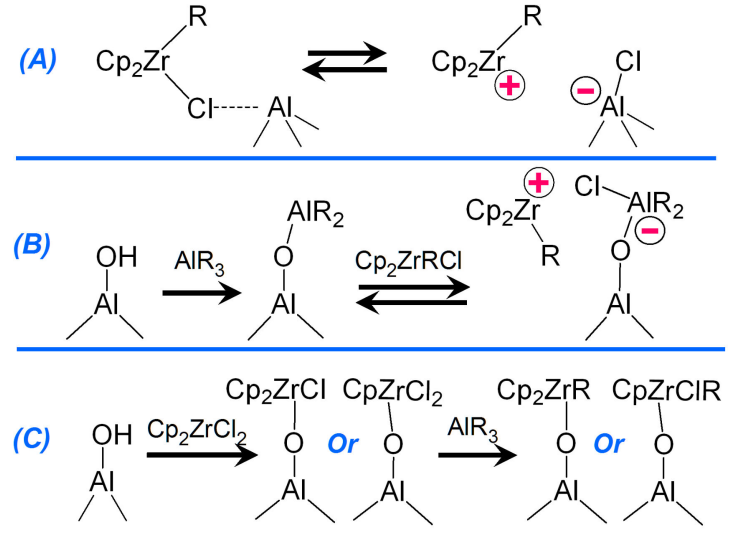

Scheme 4. Three pathways in which solid acids could activate metallocenes: (A) by Lewis acid sites, (B) by Bronsted sites converted to Lewis, and (C) directly by Bronsted sites.

However, this does not mean that there is never any interaction between the support and the $\mathrm{Zr}$ in the metallocene. When the rings are without substituents, some subtle broadening can sometimes be seen. Or, if one ring is absent as in a "half-sandwich" compound, and other ligands are unobstructive, then broadening can become still more apparent. The broadening can be extreme if both rings are absent, as with the Ballard compounds ( $\mathrm{ZrR}_{4}$ where $\mathrm{R}=$ benzyl, neopentyl, trimethylsilylmethyl, etc.) [62].

Bronsted sites on the solid acid can also react, as illustrated in Scheme 4B,C. The presence of high amounts of aluminum alkyl, compared to the metallocene, greatly favors the $4 \mathrm{~B}$ pathway over $4 \mathrm{C}$. In this manner a Bronsted site can potentially be converted into a Lewis site. However, under some conditions the pathway in Scheme $4 \mathrm{C}$ does become significant, such as: 1) when the solid acid is allowed to react with the alkylated metallocene before aluminum alkyl is added, or 2) when the aluminum alkyl concentration becomes very low. In such cases a direct bond is probably formed to the solid acid [63], and high degrees of MW broadening can result, usually indicated by the presence of greatly reduced activity and a very high-MW tail. Scheme $4 \mathrm{C}$ is also representative of how the Ballard catalysts attach, which produce polymers with very broad MW distributions.

Scheme 4B illustrates that the trialkylaluminum "cocatalyst" plays several roles beyond a mere alkylating agent. In fact, pre-alkylated metallocenes are not very active when run with solid acids in the absence of a cocatalyst, even in the absence of Bronsted sites. Thus, $\mathrm{AlR}_{3}$ probably also acts as a coordinating or solvating agent to stabilize and separate the ion pair formed during ionization in Scheme $4 \mathrm{~A}, \mathrm{~B}$. That is, it may coordinate with either the positive, negative, or both ions. The former, coordination with the $\mathrm{Zr}$, could be similar to such species long proposed for the activation of Ziegler catalysts.

Finally, the Phillips catalyst version of Scheme $4 \mathrm{C}$ would be analogous to the organochromium catalysts $[3,8,27,29,30]$. That is, the support is first calcined, then an organochromium compound is deposited, such as chromocene [64], or the "open-ring" chromocene (2,4dimethylpentadienyl) $[8,30,65,66]$, or bis- or tetrakis-neopentyl $\mathrm{Cr}$ and bis- or tetrakistrimethylsilylmethyl [29,67], or diareneCr(0) [68], etc. The Cr compound reacts with Bronsted sites on the surface, attaching as in Scheme $4 \mathrm{C}$ by losing one or two ligands. Such Phillips catalysts can be quite active and they tend to produce high-MW polymer like that 
from the classical Phillips catalyst as depicted in Scheme 1. However, the catalyst is much more active when the organo-Cr compound reacts with acidic sites on the support. Silanols on plain silica are often rather unreactive in comparison, and to use silica, as the support some heating may be necessary to force reaction with the organo-Cr compound. Consequently, such organo-Cr Phillips catalysts tend to be extremely sensitive to the Bronsted acidity of the support.

For example, dicumene $\mathrm{Cr}(0)$ is barely reactive with calcined silica at $25{ }^{\circ} \mathrm{C}$, generating little polymerization activity. However, it is a completely different story when dicumene $\operatorname{Cr}(0)$ is deposited onto an aluminophosphate support [69-72]. There is an immediate reaction, obvious from the color change, and the catalyst displays exceptional polymerization activity.

In another example, $\mathrm{Cr}\left(-\mathrm{CH}_{2} \mathrm{Si}\left(\mathrm{CH}_{3}\right)_{3}\right)_{2}$ and especially $\mathrm{Cr}\left(-\mathrm{CH}_{2} \mathrm{Si}\left(\mathrm{CH}_{3}\right)_{3}\right)_{4}$ are barely active for ethylene polymerization when deposited onto calcined alumina [29]. However, if 2-3\% fluoride is added to the alumina prior to calcination, the activity becomes quite high when treated with one of these same organo-Cr compounds. If the alumina is also impregnated with a small amount of ethyl orthosilicate, along with the fluoride, prior to calcination, the activity becomes phenomenal when treated with one of these same organo-Cr compounds [72]. The conventional Phillips catalyst, with the $\mathrm{Cr}$ annealing step, is also often responsive to these support modifications. Some examples of this will be presented in the sections below.

\subsubsection{Attachment and Ligation on Silica and Alumina}

Acidity on the support clearly plays a strong role in the formation of both Phillips and CPC metallocene catalysts. Nevertheless, the most widely used Phillips catalyst support, silica, offers no Lewis acidity, and the silanols are also barely acidic, if at all. Consequently, and without surprise, metallocenes could not be activated by silica. In contrast, silica is one of the best supports for the Phillips catalyst. Apparently, silica offers an optimum combination of: 1) silanol spacing that can accommodate chromate or dichromate surface species, and 2) poor coordination of the surface with the reduced Cr. In the absence of acidity on the support itself, the electron deficiency (Lewis acidity) on the $\mathrm{Cr}$ that is required for polymerization is apparently generated by the surface annealing that accompanies high calcination temperature (Scheme 1). At low calcination temperatures $\left(\sim 400^{\circ} \mathrm{C}\right)$ silica is relatively poor as a support for the Phillips catalyst, displaying very low polymerization activity.

The second most widely used support, alumina, is also complex in this context $[9,73]$. As a support for the Phillips catalyst [3,26,29], alumina produces only a tenth of the activity of silica, even at the highest calcination temperatures. The hydroxyl groups on alumina are not very acidic, and might even be described as basic or amphoteric. Metallocenes on alumina also provide only a trace of activity. This might be explained by the presence of $\mathrm{Al}$ ions on the surface that are considered as weakly Lewis acidic.

However, the addition of electron-withdrawing anions to alumina increases the acidity of both Lewis and Bronsted sites [74]. These anions include halides, sulfate, phosphate, triflate, trifluoroacetate, and many others. Consequently, both Phillips and metallocene catalyst activity greatly increase when the alumina support includes these anions. This will be described further in the sections below.

\subsubsection{Ligation on Mixed Oxide Supports}

Some of the supports displaying the strongest acidity are made by the combination of two oxides. For example, neither silica nor alumina are known as particularly strong acids, but the combination, silica-alumina, usually displays very strong acidity. Other examples include silica-titania [3,75], silica-zirconia [3,76], and alumina-boria [3,77,78]. The combination can be obtained through cogellation of the two oxides, or by coating, that is, depositing one oxide on the other. Phillips catalysts often show improved activity when supported on many of these mixed oxides. One of the most prominent examples 
is silica-titania. A small amount of titania, added to $\mathrm{Cr} /$ silica, can increase its activity by several fold. The MW distribution is also broadened by the addition of more polymer in the mid- to low-MW side of the distribution. An example of this is shown in Table 1 in which a standard $\mathrm{Cr} /$ silica catalyst was coated with varying amounts of titania. In addition to the activity and MW moments, the amount of long-chain branching (LCB) found in the polymer is also listed in Table 1 as a function of titania content. LCB is further discussed in the sections below [79-82].

Table 1. The influence of titania, when applied to $\mathrm{Cr} /$ silica, on the catalyst activity and resultant polymer properties.

\begin{tabular}{ccccc}
\hline $\begin{array}{c}\text { Titania } \\
\text { Ti/nm }\end{array}$ & $\begin{array}{c}\text { Activity } \\
\text { kgPE/gCat/h }\end{array}$ & $\begin{array}{c}\mathbf{M}_{\mathbf{W}} \\
\mathbf{k g} / \mathbf{m o l}\end{array}$ & $\begin{array}{c}\text { MW Breadth } \\
\mathbf{M}_{\mathbf{W}} / \mathbf{M}_{\mathbf{N}}\end{array}$ & $\begin{array}{c}\text { LCB } \\
\text { per 10 }\end{array}$ \\
\hline 0.00 & 1.9 & 158 & 7.9 & 2.8 \\
0.25 & 3.4 & 152 & 9.3 & 3.4 \\
0.50 & 3.8 & 143 & 12.3 & 5.1 \\
0.80 & 4.5 & 134 & 16.2 & 7.0 \\
1.10 & 4.7 & 128 & 17.5 & 7.3 \\
1.40 & 4.7 & 120 & 18.8 & 7.7 \\
2.20 & 4.2 & 112 & 21.3 & 10.3 \\
\hline Cr/silica treated with varying levels of $\mathrm{Ti}, 650^{\circ} \mathrm{C} \cdot$ Polymerization in isobutane at $105^{\circ} \mathrm{C}$. &
\end{tabular}

$\mathrm{Cr} /$ silica treated with varying levels of $\mathrm{Ti}, 650{ }^{\circ} \mathrm{C}$; Polymerization in isobutane at $105^{\circ} \mathrm{C}$.

Metallocene catalysts also display higher activity when supported on mixed oxides [83]. Whereas silica produces no activity, and alumina produces minimal activity, the silica-aluminas can produce ten times the activity of alumina. High calcination temperatures are usually favored.

The addition of electron-withdrawing anions, such as halides [3] or sulfate [84], often further increase the activity of Phillips catalysts supported on mixed oxides. The same effect is seen with the metallocenes and is sometimes even more pronounced.

\subsubsection{Similar Catalyst Formation and Behavior Allows Hybrid Catalysts}

The similar surface interaction of both Phillips and metallocene catalysts with these acidic mixed oxide supports, often makes them mutually compatible, which can offer the possibility of combining the two catalyst types into a hybrid. For example, fluorided silica-aluminas can be impregnated with $\mathrm{CrO}_{3}$, and calcined to make a Phillips catalyst. This catalyst can then in turn be impregnated with a metallocene compound, which also becomes active, but often without badly poisoning the chromium reactivity. Other supports can also be used for this purpose, such as sulfated boria-alumina, or fluorided silica-titania. Sometimes it is useful to first reduce the Phillips catalyst in $\mathrm{CO}$ to a $\mathrm{Cr}$ (II) state, so that it cannot oxidize the other ingredients.

Such hybrid catalysts can be used for a host of purposes. For example, if the chromium to metallocene ratio is very low, then a small, barely visible, high-MW tail is added to the usual narrow metallocene MW distribution. This tail greatly increases the polymer melt strength and changes its flow characteristics. It even increases the bulk density of the polymer granules in the reactor, because the long chains tend to hold the polymer particles together so that they better resist mechanical breakage.

In contrast, if the chromium to metallocene ratio is high, certain portions of the $\mathrm{Cr}$ MW distribution can potentially be embellished. For example, if the metallocene is a good incorporator of comonomer, such as a tightly bridged compound, it can add branching to the high-MW distribution. This increases impact resistance and resistance to chemical attack (ESCR) while maintaining the exceptional melt processibility of the Phillips component.

Likewise, many combinations of the two catalyst types can potentially lead to a wide variety of special effects. One example of these hybrid catalysts is shown in Figure 1. The fluorided silica-alumina support was calcined, then treated with a combination of $\mathrm{Cr}(\mathrm{III})(\mathrm{AcAc})_{3}$ and metallocene $\mathrm{C}$ (see Materials and Methods for structure) [85]. A series of polymers were produced at a variety of chromium to metallocene ratios. In this particular 
example the chromium produced an extremely broad MW distribution and the metallocene produced a narrow MW distribution right in the middle of the chromium contribution. Notice that many different MW distributions were produced from the combination of these two components on the same support.

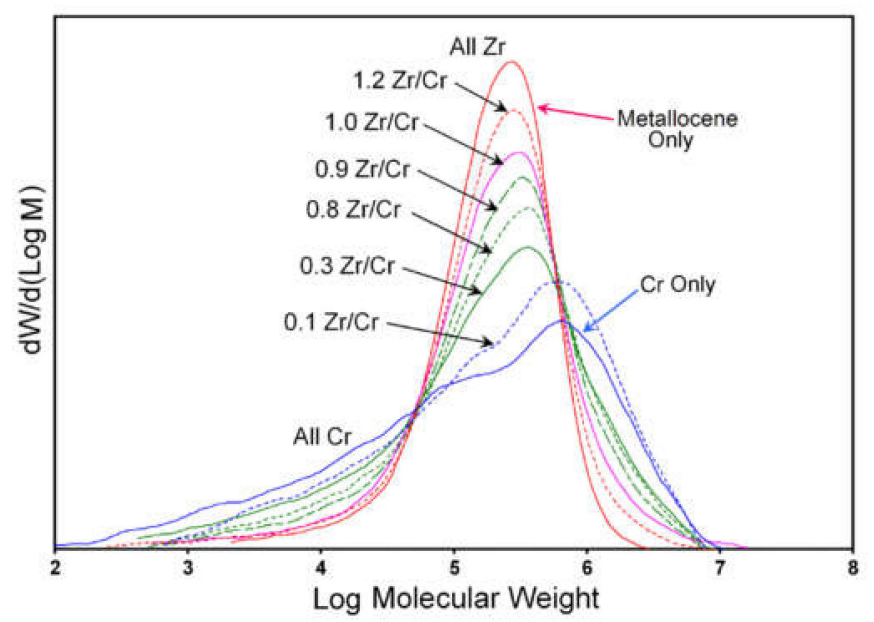

Figure 1. MW distribution of polymers produced by combinations of chromium and metallocene catalysts on the same support.

Of course, in principle the two components, $\mathrm{Cr}$ and $\mathrm{Zr}$, could be deposited onto separate supports, and then the two catalysts are combined in the reactor. However, since each catalyst particle makes a polymer particle, this approach usually results in non-homogeneous polymer powder in which the largest and highest-viscosity particles are not fully blended with the others during extrusion. Such particle heterogeneity typically produces visual imperfections in molded articles, such as "gels" or "specks," a sandpaper texture, printing problems, and even loss of mechanical properties due to poor "knitting" between the polymer particles. Thus, the ability to place the two components onto a single support is a great advantage, because the various PE chains produced are already well mixed on a molecular level even before extrusion, and consequently, each polymer particle tends to be like all the others.

\subsection{Influence by Physical Characteristics of the Support}

\subsubsection{The Influence of Surface Area and Surface Coverage on Activity}

Another point of similarity between the Phillips and metallocene catalysts is the effect of surface coverage, or metal loading, on the catalyst activity. The support itself contributes no polymer, of course. But when a tiny increment of $\mathrm{Cr}$ or $\mathrm{Zr}$ is added, catalyst activity is created, although still small at the lowest loadings. By activity, we mean the yield in $\mathrm{kg}$ of polymer produced per gram of the overall catalyst (mainly the support) per hour. As more of the active metal is added the activity of the catalyst rises. However, at some point saturation seems to be reached and the activity levels off, thus making the surface area of the support very important. With still more metal added, the activity eventually declines, possibly due to blockage or self-poisoning. This is shown in Figure 2 for both a Phillips catalyst $\left(2 \mathrm{~A}, \mathrm{Cr} /\right.$ silica, $850^{\circ} \mathrm{C}$ ) and a metallocene catalyst (2B). Metallocene A (see Materials and Methods section) on fluorided silica-alumina was used. Notice that the coverage is plotted per unit of surface area in an effort to normalize this behavior. 

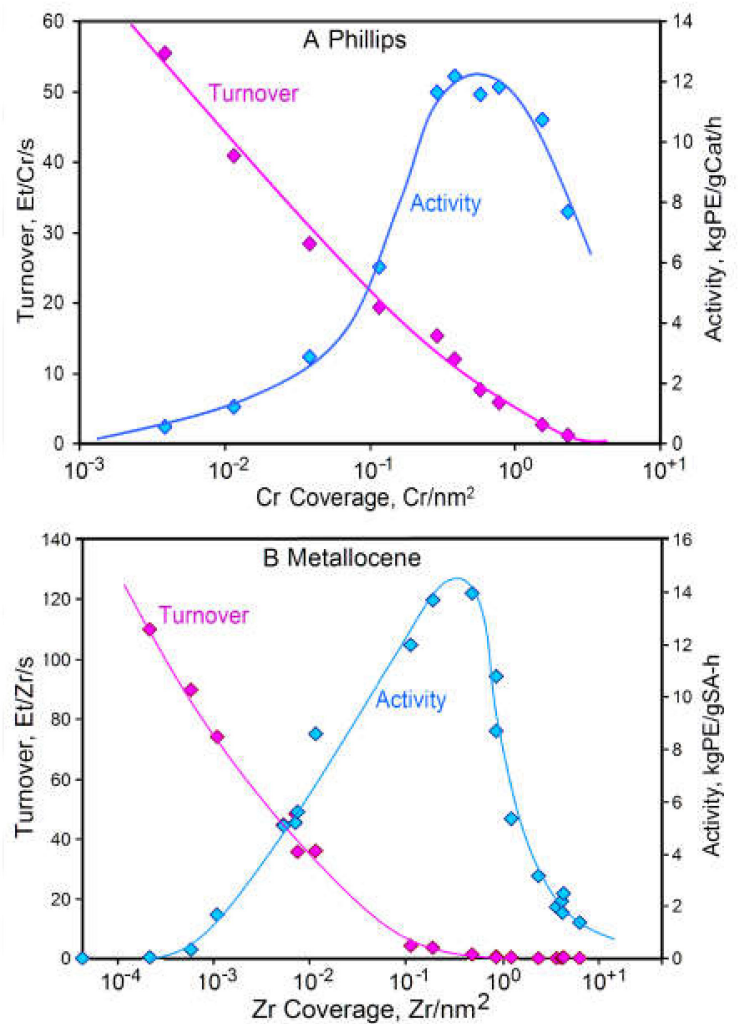

Figure 2. Overall activity and metal turnover for Phillips ((A), above) and metallocene ((B), below) catalysts as a function of metal loading.

In a somewhat different measurement, one can also calculate the average turnover frequency, that is, the number of ethylene molecules consumed per metal atom per second. This too is shown in Figure 2. Notice that the initial turnover is highest for both Phillips and metallocene catalysts when the first increment of metal is added. As more metal is added the turnover declines. Hogan first observed this behavior [5] for Phillips catalysts and it has since been found for metallocene catalysts as well $[37,38]$.

This decline in turnover with increased loading has been explained in various ways. Hogan thought that the first sites formed had found favorable locations that quickly filled up, and then sites formed at higher loadings either had lower activities or no activity. There is indeed a loading on both plots in Figure 2 where further addition of metal does not generate further activity, and only serves to bring the average turnover down. Hogan's idea could translate to metallocenes as a tendency for the most acidic sites to be occupied first, and those sites are probably also the most active.

However, the strikingly similar behavior of the two catalysts with respect to turnover raises another possible explanation: diffusion. By this idea, the polymer can inhibit monomer transport, and therefore catalysts with the lowest loadings have the advantage because they do not produce much polymer. While intriguing, this argument does have some problems. First, it has not been confirmed by model calculations. Second, it is observed in solution polymerization too, where the polymer goes into solution as it is formed. Third, by this reasoning, one might expect the kinetic profile to decay quickly for all catalysts, but Phillips catalysts usually have a rising and then flat profile after the induction time. Currently this shared behavior still waits to be adequately explained.

\subsubsection{The Influence of Support Porosity on Catalyst Activity}

Another similarity between Phillips and metallocene behavior is the dependence of their activity on the porosity of the support. High pore volume catalysts tend to be most active. This has been explained for Phillips catalysts [86-88] as being due to the necessity 
of fragmentation, caused by polymer buildup in the pores. That is, to be active, the support particle must disintegrate during polymerization into billions of small fragments that then become engulfed in polymer. To be fragile enough to fracture, high pore volume is preferred for silica and many other supports. However, by comparing the activity per square meter of surface, for a wide variety of silica types, it was also clear that large pores allow better egress of polymer from the fragments, even when the silica structure is particularly resistant to fragmentation [86].

The same reasoning should also apply to metallocene catalysts, and indeed their historical development has been largely a matter of mimicking the porosity of successful Phillips catalysts. One example of this is shown in Table 2, in which two silicas were used to produce a Phillips catalyst and three different types of metallocene catalysts. Silica A was chosen as a structurally weak support, with high pore volume $(2.6 \mathrm{~mL} / \mathrm{g})$, whereas Silica B represents greater strength, with a low pore volume $(1.0 \mathrm{~mL} / \mathrm{g})$. Silica A had much larger pores, with an average diameter of about 4.5 times that of Silica B. As expected, when these two silicas were converted into Phillips catalyst, Silica A provided about four times higher activity than Silica B.

Table 2. Two silicas were used as a support in the preparation of $\mathrm{Cr}$ and three metallocene catalysts. In each case the less porous silica provided lower activity.

\begin{tabular}{ccc}
\hline Silica & A & B \\
\hline Pore volume, $\mathrm{mL} / \mathrm{g}$ & 2.6 & 1.0 \\
Surface area, $\mathrm{m}^{2} / \mathrm{g}$ & 350 & 600 \\
Avg. pore diam., Ang & 297 & 67 \\
& Activity, kgPE/h per mol Cr or Zr & 4.2 \\
Catalyst type 1 (Cr) & 16.6 & 7.7 \\
Catalyst type 2 (met) & 103 & 3.7 \\
Catalyst type 3 (met) & 29.7 & 4.6 \\
Catalyst type 4 (met) & 47.2 & \\
\hline
\end{tabular}

Catalyst 1: $1 \mathrm{wt} \% \mathrm{Cr}$ on silicas, calcined at $700^{\circ} \mathrm{C}$, ethylene at $105^{\circ} \mathrm{C}$; Catalyst 2: silicas impregnated with $\mathrm{HBF}_{4}$ and then calcined at $450^{\circ} \mathrm{C} ; 8.7$ micromol metallocene $\mathrm{C}$ per g silica, ethylene at $90^{\circ} \mathrm{C}$; Catalyst 3: silicas treated with $\mathrm{Ti}$, then $\mathrm{NH}_{4} \mathrm{HF}_{2}$, calcined at $450{ }^{\circ} \mathrm{C} ; 8.7$ micromol metallocene A per g silica, ethylene at $100{ }^{\circ} \mathrm{C}$; Catalyst 4 : silicas treated with $\mathrm{Ti}$, then $\mathrm{NH}_{4} \mathrm{HF}_{2}$, calcined at $450{ }^{\circ} \mathrm{C} ; 8.7$ micromol metallocene $\mathrm{B}$ per $\mathrm{g}$ silica, ethylene at 90 ${ }^{\circ} \mathrm{C}$; Met structures: $\mathrm{A}=(\mathrm{n}-\mathrm{bu}-\mathrm{Cp})_{2} \mathrm{ZrCl}_{2} \mathrm{~B}=\operatorname{rac}-\mathrm{Et}(\mathrm{Ind}){ }_{2} \mathrm{ZrCl}_{2} ; \mathrm{C}=\mathrm{C}\left(\mathrm{CH}_{3}\right)(\mathrm{Bu})(\mathrm{di}-\mathrm{t}-\mathrm{Bu}-\mathrm{Flu})(\mathrm{Cp}) \mathrm{ZrCl}_{2}$. Another example of the influence of porosity is shown in Figure 3. A variety of silica-aluminas were made by cogellation and then the pore water was replaced by another solvent through washing or distillation. These various solvents differed widely in surface tension, so that a wide variety of porosities resulted upon drying. One portion of each support was then converted into a Phillips catalyst, by impregnation of $\mathrm{CrO}_{3}$ and calcination at $500{ }^{\circ} \mathrm{C}$. Another portion of each support was converted into a metallocene catalyst, by impregnation of ammonium bifluoride, followed by calcination at $500^{\circ} \mathrm{C}$ and contact with metallocene $\mathrm{C}$.

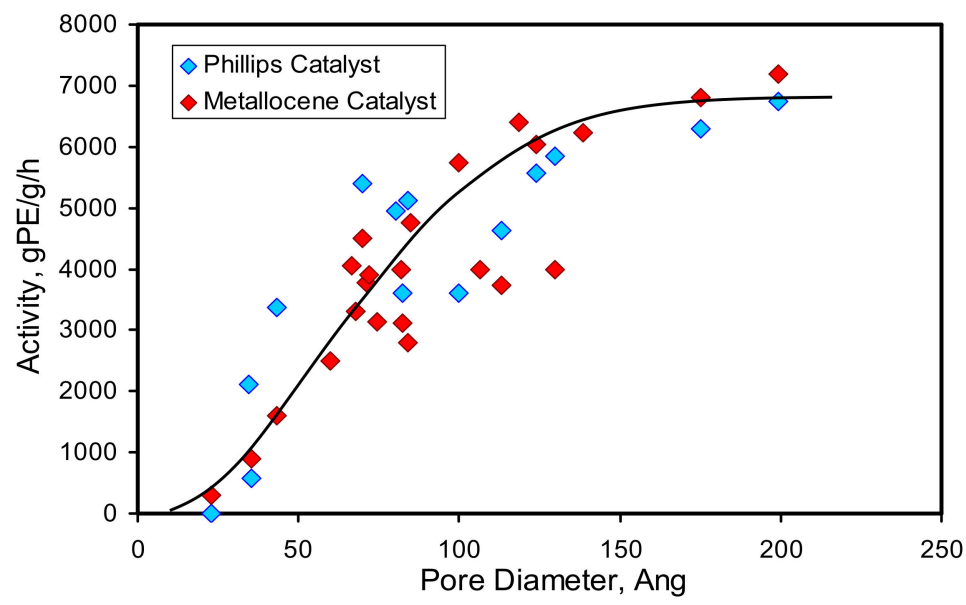

Figure 3. Cogelled silica-alumina were made into Phillips or metallocene catalysts. 
The same two silicas were then used to make metallocene catalysts by three different recipes. Since silica itself does not activate metallocenes, the two silicas were first impregnated with a Lewis acidic component. In the first recipe fluoroborate was used, whereas in the other two recipes the silica was first titanated, then fluorided. Three different metallocenes (A, B, and C) are also represented in these experiments. Notice in each case, however, that once again Silica A produced much higher activity that Silica B, by about an order of magnitude overall. Both supports produced commercially acceptable polymer granules. The porosity, or bulk density, of the polymer should not be confused with that of the support. They are usually not related, at least within the commercial porosity range (0.5 to $3.0 \mathrm{~mL} / \mathrm{g}$ PV).

In Figure 3 the activities obtained from these two sets of catalysts are plotted as a function of the pore diameter. Pore volume could also have been used, since the surface area of these catalysts were relatively constant at $500{ }^{\circ} \mathrm{C}$. Both catalyst series fall on the same S-shaped line, which was also reported for other Phillips catalysts [3,79,86-88]. Clearly porosity limits the activity of metallocene catalysts in the same way, and by the same rules, as it does for Phillips catalysts.

\subsubsection{The Influence of Polymer Yield on Long-Chain Branching}

Another surprising point of similarity between Phillips and metallocene catalysts is their dependence on polymer yield. The first polymer made always seems to contain the most long-chain branching (LCB). LCB arises from the incorporation into the growing chain of previously formed "dead" chains, called "macromers," which often contain a reactive terminal vinyl end-group. Scheme 5 illustrates the process, which is discussed in more detail in the sections below.

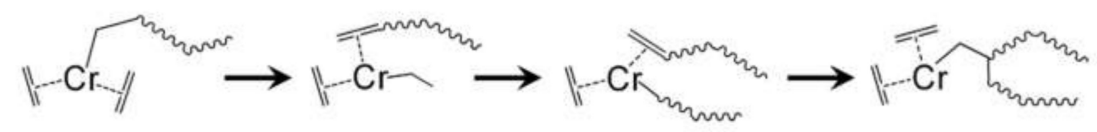

Scheme 5. LCB formation by $\beta-\mathrm{H}$ elimination and later insertion of the macromer.

Figure 4 shows an example of this behavior. In Figure $4 \mathrm{~A}$, a $\mathrm{Cr}$ / silica-titania catalyst $\left(870{ }^{\circ} \mathrm{C}\right)$ was allowed to polymerize ethylene for various times, then the reaction was stopped. Rheology was obtained on each sample and the average LCB content was determined through the Janzen-Colby relationship [43] which relates melt viscosity to the weight-average molecular weight $M_{W}[3,79]$. LCB becomes entangled with linear chains, and then resists disentanglement during flow, especially at low-shear rates. This provides a very sensitive method of detecting and measuring tiny amounts of LCB. 

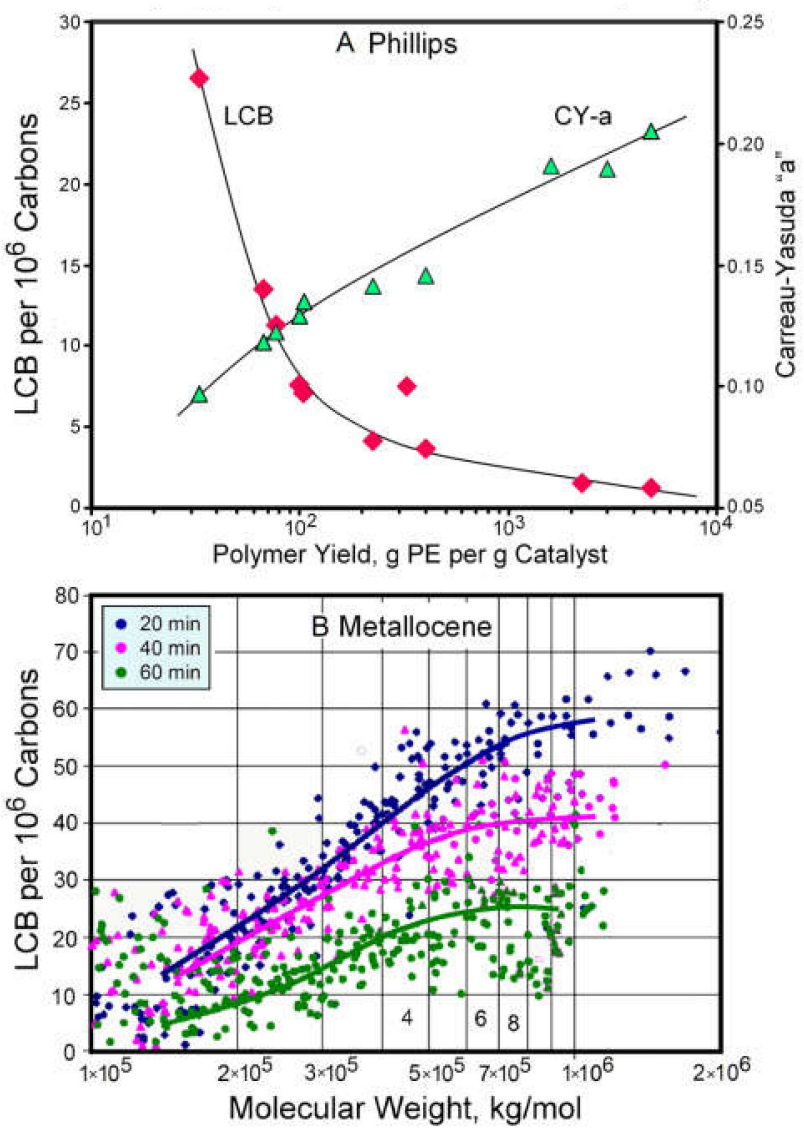

Figure 4. Reaction time was varied for $\mathrm{Cr}$ / silica-titania (A above) and $\mathrm{rac}$ - $\mathrm{Et}(\mathrm{Ind})_{2} \mathrm{ZrCl}_{2}$ on fluorided silica-alumina (B below).

In Figure 4A the measured LCB content is plotted as a function of the amount of polymer made per gram of catalyst, e.g., the polymer "yield," which of course is also equivalent to polymerization time. Notice that the amount of LCB detected is very high in the early (low yield) stages of polymerization, and then it drops rather sharply with rising yield or time.

The other value that is plotted in Figure 4A is the "a" parameter from the CarreauYasuda relationship [42] which is usually abbreviated "CY-a." It represents the breadth of the relaxation time distribution. It works as a convenient surrogate for LCB because LCB always has a large effect on this parameter. The CY-a goes down as LCB goes up. Therefore, in Figure $4 \mathrm{~A}$ the $\mathrm{CY}$-a increases with rising polymer yield. This indicates a narrowing of the breadth of the relaxation time distribution, caused by a decline in LCB content. Therefore, both parameters indicate that the first polymer made has the highest LCB content, which then drops with increasing reaction time or yield.

In Figure $4 \mathrm{~B}$ the same experiment was performed using a metallocene catalyst (metallocene B) on fluorided silica-alumina. After starting the polymerization, it was then stopped after $20 \mathrm{~min}$. In the second and third experiments the polymerizations were stopped after $40 \mathrm{~min}$ and after $60 \mathrm{~min}$ respectively. The analysis technique used in Figure 4B was also different. Instead of using rheological parameters, the polymers were analyzed by means of size-exclusion chromatography multi-angle light scattering (SEC-MALS) [45]. This method compares the volume occupied by polymer chains in solution as a function of molecular weight. Branched chains occupy a smaller volume in solution than linear ones, which SEC then translates into a measure of LCB content. In Figure 4B it is plotted as a function of molecular weight.

Notice in Figure 4B that the sample stopped after $20 \mathrm{~min}$ produced the highest concentration of LCB, and that LCB then dropped with longer reaction time (yield) in this series. This is 
consistent with the rheological measurements in Figure 4A. In fact, rheological measurements on similar metallocene polymers show the same trends as in Figure 4A. Likewise, SEC-MALS measurements on Phillips polymers show the same trend as in Figure 4B [80].

In such experiments, PE yield and reaction time are equivalent as variables, and it is unclear which one actually drives this behavior. Yield seems the more likely cause, given that the behavior is observed from quite different catalyst chemistries. This makes it less likely to be caused by a chemical change occurring with time on the catalysts. Diffusion issues have been cited as a cause, under the assumption that monomer transport becomes increasingly difficult with rising polymer yield. But this would result in decreasing ethylene concentration around the active site with higher yield, producing higher LCB. This runs opposite to the behavior shown in Figure 4. Lower activity (a declining kinetic curve) would also be expected with rising yield, which is not usually observed with Phillips catalysts.

Another possible explanation relates to fragmentation $[3,86,88]$. Low pore volume supports tend to produce low activity and high LCB. The low pore volume makes the matrix stronger and less likely to fragment. The lower degree of fracturing that does occur probably leaves larger fragments. Therefore, more of the polymer is conceivably made inside pores rather than on the exterior of the fragments. The polymer made inside pores may be higher in LCB because of the difficulty, inside a crowded pore, of macromer disconnecting from the site (see Scheme 5). This theory fits the much-studied response of Phillips catalysts to porosity.

Consistent with this idea is the fact that the structure of $\mathrm{Cr}$ / silica can be reinforced by impregnation of small amounts of silicates before calcination. This treatment also greatly increases LCB, probably by making the matrix more difficult to fragment during polymerization [89].

By extension of this theory, the very first polymer made, before fragmentation begins, is entirely made inside pores. After fragmentation, that initial high-LCB polymer is diluted with lower-LCB material made on the exterior of the fragments. This would fit the typical precipitous drop in LCB shown in Figure 4A [79].

\subsection{Influence of Support Acidity on Activity and Long-Chain Branching}

\subsubsection{Macromer Retention and the Effect of Acidity}

With both Phillips and metallocene catalysts, we often observe a positive correlation between the strength of acid groups on the support and the amount of long-chain branching in the polymer. It seems likely that it is electron deficiency on the metal that drives the formation of LCB. This deficiency is in turn probably influenced by acidity on the support to which the $\mathrm{Cr}$ is attached on Phillips catalysts. Notice in Table 1 that long-chain branching was increased by the addition of titania to $\mathrm{Cr}$ / silica catalyst.

As a general trend, stronger acidity has usually been associated with a rise in LCB from metallocene catalysts as well. The increase in positive charge on the metal (that is, an increase in electron deficiency) is thought to increase its attraction to $\alpha$-olefins, thus increasing the chance of macromer retention and later insertion [3,54,79-82]. The mechanism is illustrated in Scheme 5.

For metallocenes, that influence of the support may also be thought of as occurring through another path. Notice the lower reaction in Scheme 2 or Scheme $4 \mathrm{~A}$, both of which show the metallocene in equilibrium between the neutral (inactive) species and the ionized (active) form. The amount of time spent in each form (the equilibrium constant) may depend on the acidity of the support. Since only the ionized form, and not the neutral species, can coordinate and retain macromer as shown in Scheme 5, LCB content could therefore be a function of this timing. A short residence in the active form, relative to the time needed for creation of another chain, would tend to release macromers before they can be incorporated.

Schemes 2 and 4A might be considered as a formalism and actually the $\mathrm{Zr}$ can be "partially ionized" to varying degrees, resulting in varying reactivities. By this view, the $\mathrm{Zr}$ 
can have different levels of electron deficiency, resulting in different amounts of LCB, from various supports, or even from different sites on the same support.

Scheme 6 illustrates the tendency of these two catalysts to coordinate to $\alpha$-olefins. This includes "dead" chains, or macromers, which are terminated by $\beta-\mathrm{H}$ elimination to form a terminal vinyl end-group. In the upper group of pictures (Scheme 6A), the colored metallocene D was dissolved in toluene [54]. In the first picture, liquid MAO has been added to toluene in the bottle. Notice that it has no color, but the metallocene solution in the syringe is orange. In the second picture, the metallocene has been injected into the MAO to produce a red-violet solution. In the third picture, ethylene has been added to produce polymer. Being insoluble in toluene at $25^{\circ} \mathrm{C}$, the polymer drops out of solution as it is formed. But notice that it also carries the color with it, indicating that the metallocene is coordinated to the polymer through the terminal vinyl group of a macromer. This coordination to macromer exists even in the presence of ethylene, because $\alpha$-olefins are better electron donors. Finally, in the last picture, $5 \mathrm{~mL}$ of 1-hexene has been added. Now the colored metallocene goes back into solution, probably because 1-hexene has displaced the macromer $[54,90]$.

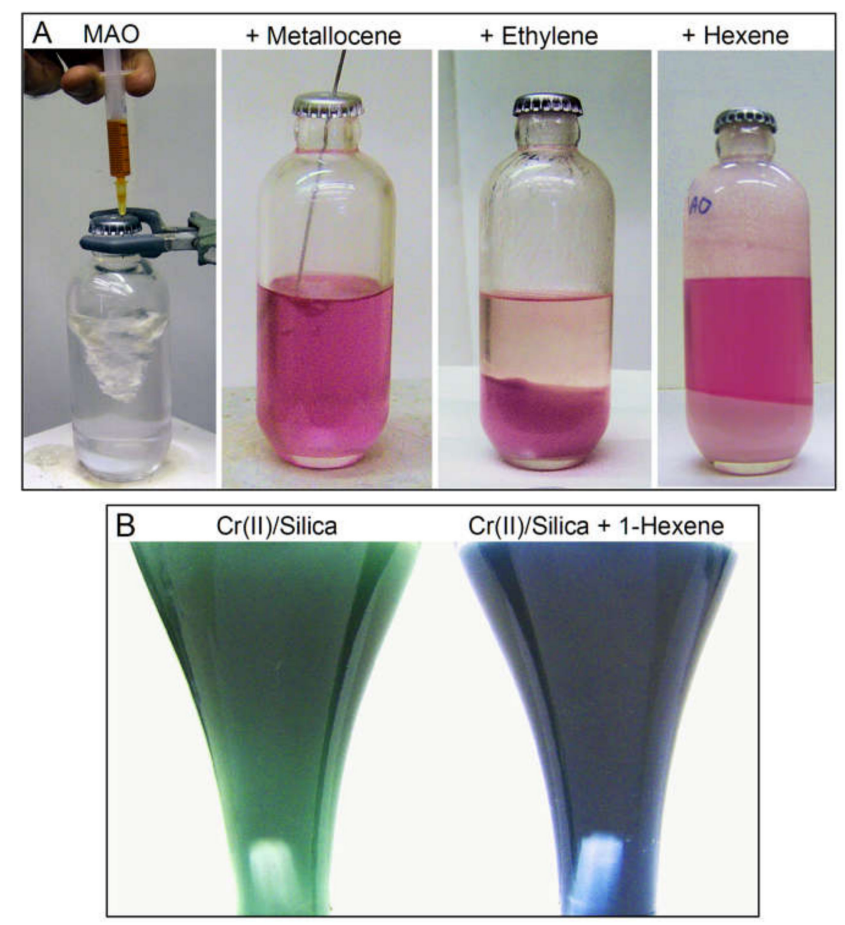

Scheme 6. Showing the tendency of ((A) above) metallocene and ((B) below) Phillips catalyst to coordinate to $\alpha$-olefins, including the terminal vinyl of a PE chain.

This visual experiment is a demonstration of the desire of these catalysts to retain macromer coordination. The effect is also supported by many other ways of studying the question, which have been previously summarized in [54,91].

In the lower group of pictures (Scheme 6B), a divalent Phillips catalyst is shown, that is, $\mathrm{Cr} /$ silica-titania calcined at $870{ }^{\circ} \mathrm{C}$ and then reduced by $\mathrm{CO}$ at $350^{\circ} \mathrm{C}$. In the first picture it is in a heptane slurry which produces a green color. In the second picture 1-hexene was added. This immediately produces a royal blue color due to coordination of 1-hexene as described by Hogan [5]. However, the second picture was actually taken after stirring for two weeks. Since the divalent catalyst is quite active for the polymerization of 1-hexene, it was given this long reaction time to exhaust the monomer supply. But notice that the blue color did not go away, indicating that it is still coordinated to an olefin. The olefin could be the last traces of unpolymerized 1-hexene, but more likely it is to the polyhexene macromer. Either way, it indicates a tendency for the $\mathrm{Cr}$ to hold on to $\alpha$-olefin. 
Another indication of this tendency is the strong presence of methyl branching in polymer made at low ethylene concentration. Methyl groups result from the termination of live chains by $\beta-\mathrm{H}$ elimination. The resulting vinyl-containing macromer remains coordinated to the site, cycling back and forth between the alkyl and hydride form. Occasionally macromer mis-inserts during this process. That is, it adds back to the hydride in a 2,1 orientation instead of the usual 1,2 manner. This then produces a methyl branch upon further polymerization of ethylene. A more detailed explanation of this reaction can be found in [92].

\subsubsection{Measurement of Acidity}

Measurement of surface acidity on the support can be difficult. Both the strength of acid sites, and the density (concentration) of these sites, can potentially drive catalyst activity. The methods of amine or pyridine adsorption are not very useful for the discrimination of these solid acid supports. For example, simple alumina adsorbs more ammonia than the treated aluminas even though the former does not activate metallocenes to any significant degree $[37,38]$. Desorption of ammonia also failed to distinguish adequately.

Weaker bases, like diethyl ether, were also tested, with some degree of success. That is, supports were saturated with ether vapor, then flushed with nitrogen and allowed to polymerize ethylene. The polymerization activity was then compared with the original activity, and the difference was used as a test for Lewis acidity. This method resulted in some comparisons being made between supports, and conclusions being drawn. For example, chlorided zinc aluminate, which has only Lewis acidity, was completely killed by this treatment. In contrast, fluorided silica-alumina was unaffected [37,38]. Although interesting, this method was not very convenient, and it proved unsatisfactory for predicting activity.

Another method of acid site characterization was suggested by the Turin group, who successfully pioneered it for this purpose, and to whom we express our gratitude [93]. Infrared spectroscopy of adsorbed CO was clearly found to distinguish between Bronsted and Lewis acidity, and to differentiate between alumina and sulfated alumina, in terms of amount (site density) and peak shift (acid strength). Publication of these results may perhaps occur in the future.

Another, more convenient, method of gauging the acid strength of supports, particularly for in-plant commercial work, was also investigated, namely the method of Hammett indicators [94-99]. When adsorbed onto acid sites on a support surface, certain indicators change color reflecting an ionized or unionized state. The support can then be titrated back to the original color with butylamine in an anhydrous hydrocarbon solvent. This gives a quick indication of the amount of acid sites having certain $\mathrm{pKa}$ or lower (stronger). It does not distinguish between Bronsted and Lewis acidity, but most of the acidic supports used contain both. Therefore, the test, while incomplete, is still useful for quick feedback on known commercial samples. Some examples are shown in Scheme 7. 


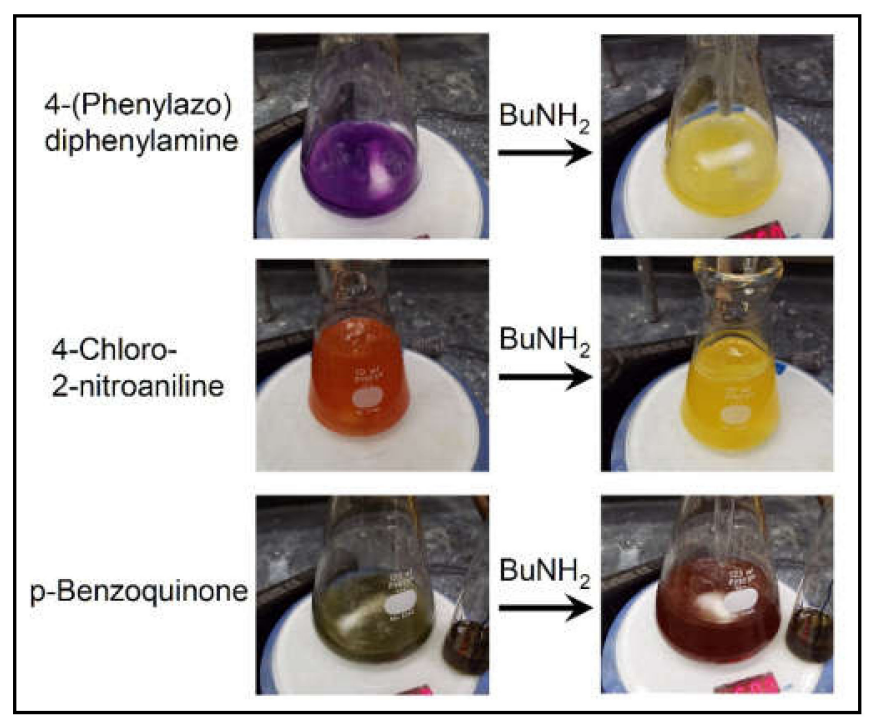

Scheme 7. One method of measuring acidity on solid oxides is by titration with butyl amine using various Hammet indicators, each sensitive to a different $\mathrm{pKa}$.

Figure 5 shows two such titrations using two solid acids: SA-1) a sulfated alumina, and SA-2) a fluorided silica-alumina. Various indicators were used, each having a different pKa. It is the derivative curves that are shown in Figure 5. In this example, one could conclude that SA-1 has more acidic sites, but that some of those on SA-2 have a greater acidic strength. Since metallocene $C$ was considerably more active on SA-2, one could infer that activity for this metallocene is a strong function of acid strength. This is what the green line represents, although this is only a hypothetical curve which would apply to both solid acids. A curve such as this would be required to explain the observed activity difference. SA-2 also produced considerably more LCB from the same metallocene, possibly from those most acidic sites, as indicated by the arrow.

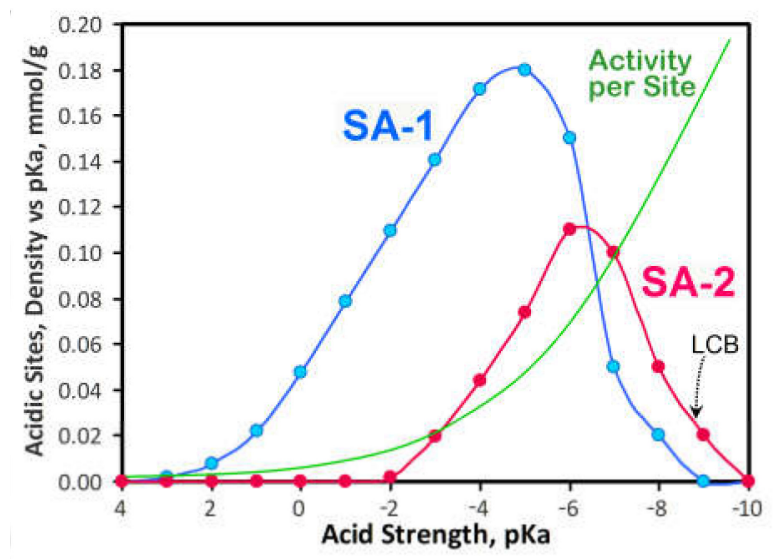

Figure 5. Hammet titrations of two solid acids: SA-1 (sulfated alumina) and SA-2 (fluorided silica-alumina).

The measured LCB found in polymers made using metallocene $\mathrm{E}$ on these two solid acids, SA-1 and SA-2, is shown in Figure 6. The SEC-MALS technique was used, and therefore the level of LCB is plotted as a function of molecular weight. Notice that SA2 produced over twice the LCB of SA-1. Of course, acid strength is only one variable potentially influencing LCB. As noted earlier, it is probably also a function of support porosity, degree of ligation and steric factors of the metallocene structure [54]. 


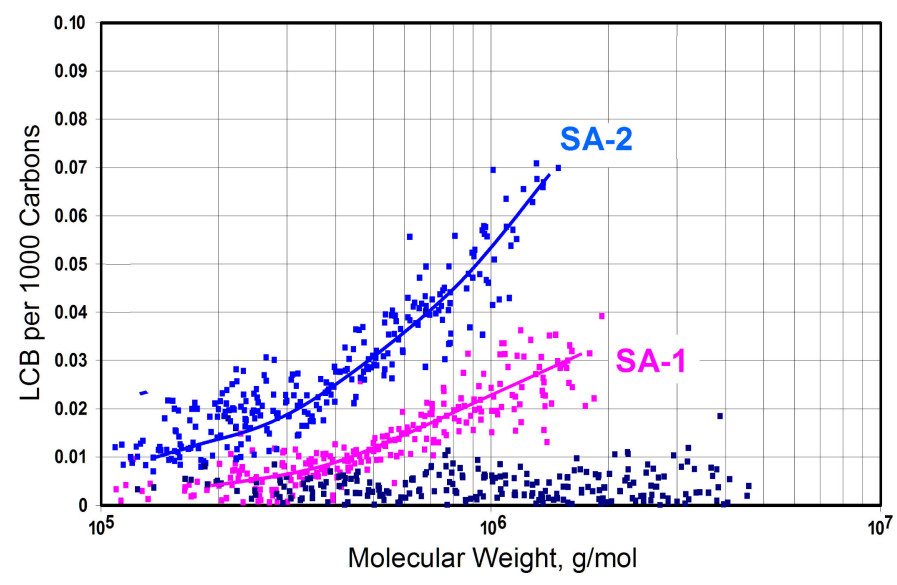

Figure 6. Light scattering analysis (SEC-MALS) of polymers from metallocene on two different solid acids: SA-1 (sulfated alumina) and SA-2 (fluorided silica-alumina).

Actually, these solid acids react with many compounds to create color besides the Hammett indicators. This especially includes aromatic polycyclic hydrocarbons and the resulting color probably involves the formation of charge-transfer complexes with acid sites [100-102]. These can also be calibrated against known acids, for example sulfuric or phosphoric acid on silica, to determine the acid strength required to cause color.

Finally, in a simplification of the Hammett method, it is also possible to just measure the color intensity as a substitute for the full titration. This makes it very easy to quickly check the quality of commercial samples during manufacturing. Although color meters were tested for this purpose, such as those used in the manufacture of polyethylene, simpler methods were also found to work, such as using the ascii color value from a photo. This served as an approximation of acid site density when the support itself was used as the "no-color" reference in a series. Some of these applications are shown in examples below.

\subsubsection{The Effect of Poisons on LCB Formation}

Given that acidity plays an important role in the formation of LCB, it would perhaps be expected that poisons, e.g. competitive electron donors, would have a detrimental effect on LCB. Hogan first noticed this for the Phillips catalyst in 1972, when he added sub-ppm traces of carbon monoxide to the reactor [103]. Observing certain changes in the polymer, he concluded that LCB formation had been suppressed. Hogan noticed that the more CO that was added, the less shear-thinning the polymer became. Shear-thinning is a direct result of long-chain branches that get entangled with other linear polymer chains. Such entanglements resist flow (disentanglement) of the molten polymer at low shear rates, but with enough strain applied they finally do disentangle and then the flow becomes much easier. Thus, the term "shear thinning" refers to the ratio of the viscosity at low-shear rates to that measured at high-shear rates.

The effect Hogan noticed is shown in Figure 7 in a plot of shear response against melt index [104]. Melt index is a widely used ASTM viscosity measurement, which measures the amount of molten polymer flow at $190^{\circ} \mathrm{C}$ under a $2.18 \mathrm{~kg}$ load and through a specific orifice. Shear response is the flow at ten times that load divided by the melt index. A high shear response can be a sign of LCB if, as in Hogan's case, the MW distribution did not change enough to affect the shear response. Notice in Figure 7 that the shear response drops for a given melt index, when $\mathrm{CO}$ was added to the reactor. Hogan realized that since the MW distribution had not changed very much, this must be the result of lower long-chain branching. 


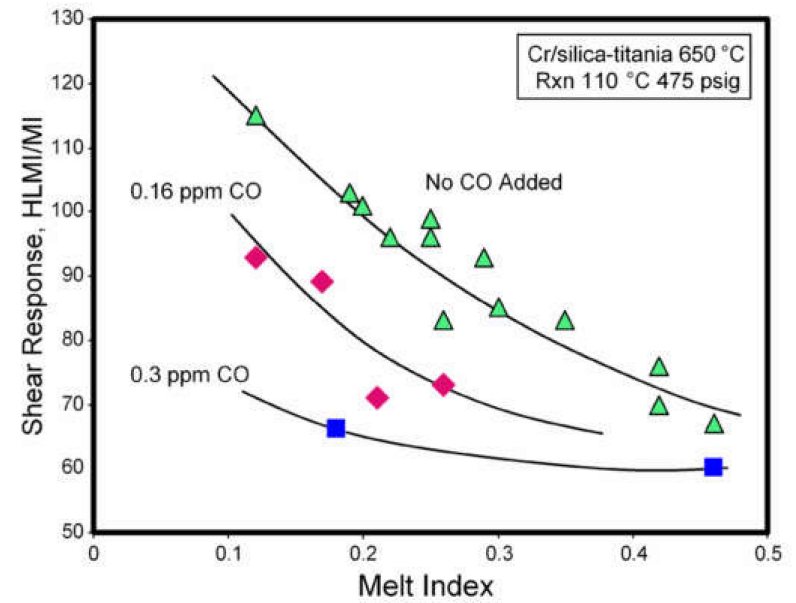

Figure 7. Adding $\mathrm{CO}$ to the reactor diminishes the shear thinning ability of the resin (HLMI/MI) due to lowered LCB.

Adding other poisons to the reactor were later found to produce similar effects with the Phillips catalyst [105]. For example, adding alcohols similarly reduced the shear response. This is shown in Figure 8A, in which ppm levels of methanol were added to the reactor. The activity dropped, and also the LCB content in the polymer. Notice that the shear response declined as the amount of methanol was increased. Melt index also decreased, indicating that the most acidic sites, which produce high melt index [3], had been poisoned first. The loss of those acidic sites correlates with the presence of titania. As discussed above, the most acidic sites, being most electron deficient, are more inclined to incorporate $\alpha$-olefin relative to ethylene. Thus, adding poisons tends to decrease short-chain branching too, raising crystallinity, and consequently the polymer density.
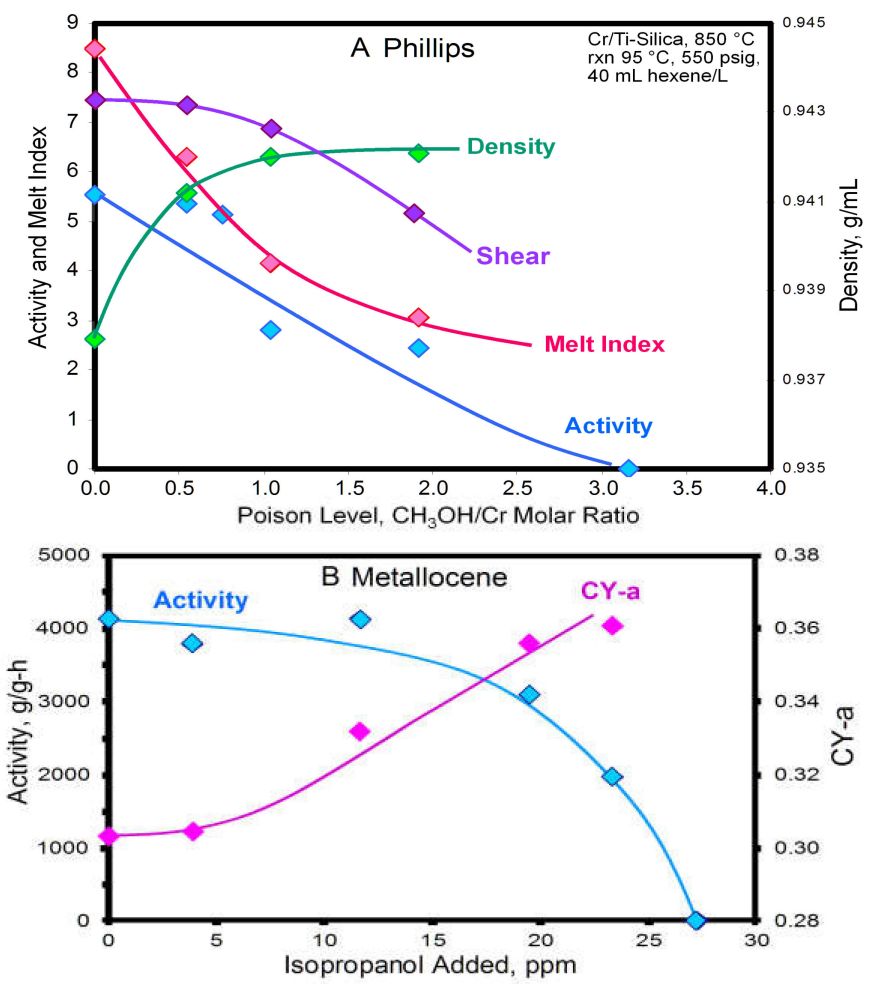

Figure 8. Effect of adding alcohol to the reactor. ((A), above): methanol to a Phillips catalyst. ((B), below): isopropanol to a metallocene on fluorided silica-alumina. 
In a similar experiment, the effect of alcohol on LCB formation from a metallocene catalyst was also tested, metallocene $\mathrm{C}$ on fluorided silica-alumina. In Figure 8B, the activity and the CY-a value are plotted as a function of the amount of isopropanol added to the reactor. Again, the activity dropped as the alcohol was added, but notice also that the CY-a parameter increased. As with the Phillips catalyst, this again indicates a reduction of the LCB content of the polymer as poison (Lewis base) was added.

In another experiment, the solid acid support was exposed to small amounts of water vapor. After calcination in a fluidized bed at $600{ }^{\circ} \mathrm{C}$, sulfated alumina was cooled to $25^{\circ} \mathrm{C}$ while still fluidizing in nitrogen. Then a small amount of water was injected into the nitrogen stream where it slowly evaporated and was carried up through the fluidizing bed. These catalysts were then tested with metallocene $C$ and the results of this experiment are shown in Figure 9A.

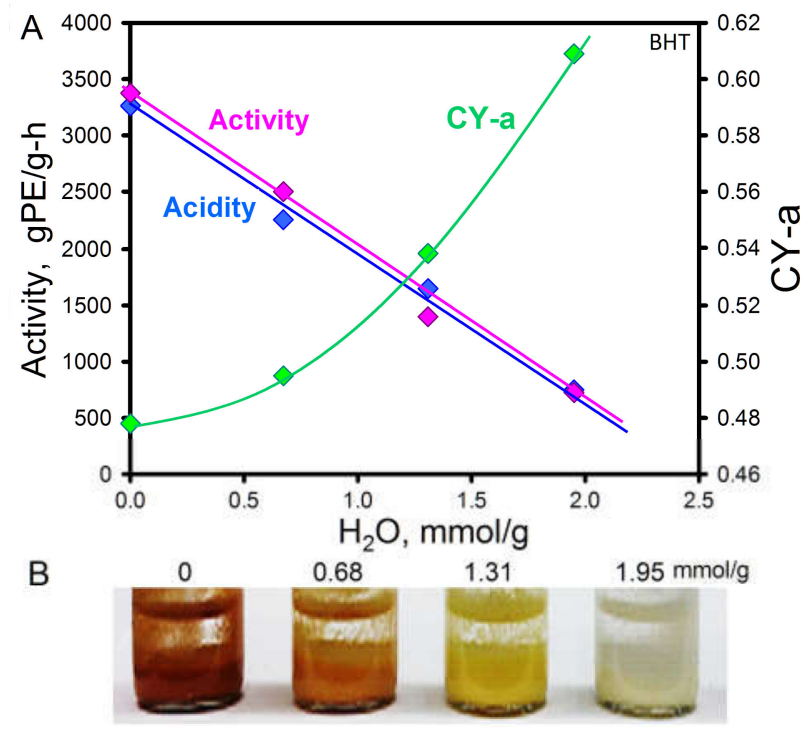

Figure 9. ((A), above): Activity and LCB from a metallocene catalyst supported on sulfated alumina declines (CY-a rises), as water is added to the solid acid. ((B), below): color generated when the treated solid acid is treated with BHT.

Notice in Figure 9A that, as expected, the activity dropped with the addition of water vapor. And, as expected, the CY-a value increased indicating a suppression of LCB formation. Shown at the bottom in Figure $9 \mathrm{~B}$ are the colors that were observed when these solid acids were exposed to BHT. In the 9A graph the intensity of the color is plotted under the title "Acidity." Other indicators produced similar changes in color. It is interesting that the color intensity and the measured activity paralleled each other in this series.

\subsubsection{The Influence of Fluoride Loading}

As noted above, catalysts supported on silica-alumina become significantly more active when fluoride is added. This applies to Phillips catalysts and also to metallocene catalysts. Figure 10 plots the activity of a Phillips catalyst, and also a catalyst using metallocene A, both supported on silica-alumina to which fluoride had been added prior to calcination at $500{ }^{\circ} \mathrm{C}$. The activities are plotted as a function of fluoride content.

Notice that the polymerization activity for both catalysts increase at first as fluoride is added. However, in both cases, the activity reaches a peak, and then declines with more fluoride addition. The initial rise in activity is probably the result of increased acidity. The later decline in activity is due to the fact that fluoride can act as a flux to thermally sinter the support. The consequent loss in surface area understandably lowers the activity. 


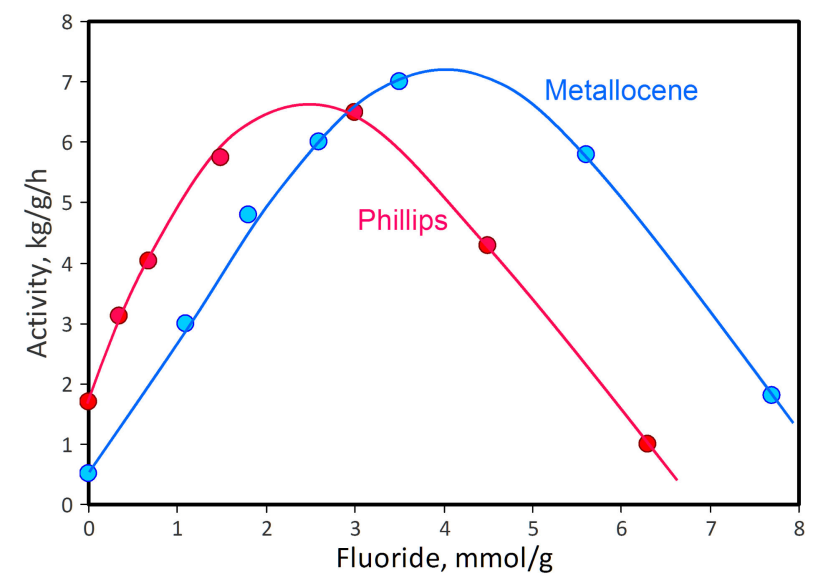

Figure 10. Activity from a metallocene and Phillips catalyst both supported on fluorided silicaalumina, as a function of the fluoride concentration.

The sintering $[37,38,106]$ is a function of both fluoride loading and temperature. Each fluoride level chosen has a peak calcination temperature, and each calcination temperature chosen has a peak fluoride level. But notice in Figure 10 that the peak fluoride level for the metallocene catalyst comes at a little higher fluoride level than that for the Phillips catalyst, even though both are calcined at $500{ }^{\circ} \mathrm{C}$.

This is probably a consequence of the two different binding modes, illustrated in Schemes 1 and 2, for the two catalyst types. Metallocene react with Lewis acid sites, which increase, either in density or strength, as the hydroxyls are replaced by fluoride, up to the point of sintering. However, Phillips catalysts require that at least some hydroxyls (or perhaps susceptible -Al-O-Si- sites) are not removed by fluoridation. The chromium reacts with these remaining Bronsted sites to bind to the support. This helps explain why the peak fluoride level is different between the two catalyst types.

\subsubsection{The Influence of Sulfate Loading}

A similar experiment was conducted in which the sulfate loading was varied on alumina. That is, alumina, calcined at $600^{\circ} \mathrm{C}$, was then impregnated with varying amounts of aqueous sulfuric acid. Chromium $\left(\mathrm{CrO}_{3}\right)$ was added for the Phillips catalysts. Then both the $\mathrm{Cr} /$ sulfated-alumina and the sulfated-alumina samples were calcined at $600{ }^{\circ} \mathrm{C}$. Metallocene $C$ was then added to those not containing $C r$. Figure $11 \mathrm{~A}, \mathrm{~B}$ plot the results of polymerization tests using these same catalysts, as a function of the sulfate level. Phillips catalysts are shown in the upper graph (Figure 11A), and metallocene catalysts in the second graph (Figure 11B). The colors generated by reaction with indene are shown in Figure $11 \mathrm{C}$ at the bottom.

Notice that with the addition of sulfate, the activity of both catalyst types rises. They both reach a peak at about the same sulfate loading, and then both decline. Unlike fluoride, sulfate does not cause sintering. Instead, with increasing sulfate or increasing temperature, sulfate begins to decompose into $\mathrm{SO}_{2}$ and $\mathrm{O}_{2}$, which has no effect on surface area or pore volume. 


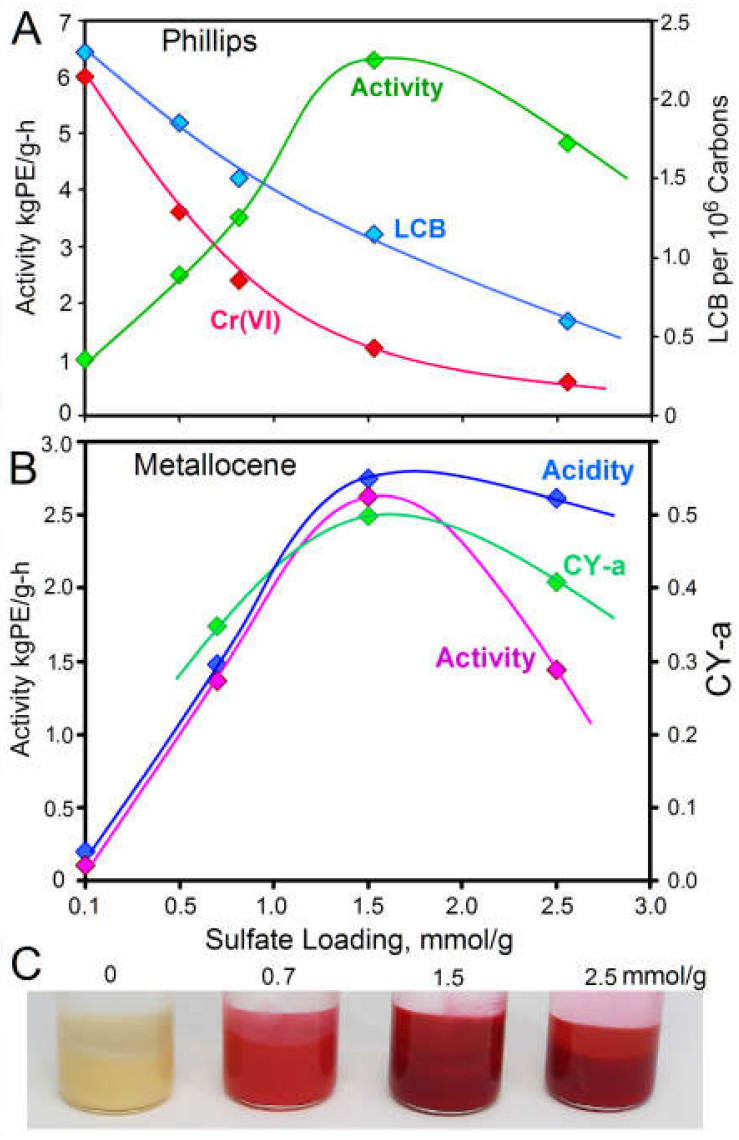

Figure 11. Activity, acidity and LCB (CY-a) from a Phillips ((A) above) or metallocene catalyst ((B) center) both supported on sulfated-alumina, as a function of the sulfate loading. ((C) below), color developed by exposure to indene.

Nevertheless, there is evidence that sulfate, like fluoride, does displace the chromium, by removing $\mathrm{OH}-$ binding sites. The conversion to $\mathrm{Cr}(\mathrm{VI})$ is plotted in Figure 11A. Notice that, as sulfate is increased, $\mathrm{Cr}(\mathrm{VI})$ declines. Consequently, when peak activity is reached, it is with a very small concentration of active $\mathrm{Cr}$ sites. Thus, peak activity represents a compromise between $\mathrm{Cr}(\mathrm{VI})$ concentration and acidity, which determines the activity per site. This suggests a curve something like the green line in Figure 5, where acid site strength may have been just as important as the number of acid sites.

Surprisingly, the addition of sulfate suppressed LCB formation by the Phillips catalyst, and it also seemed to lower LCB (raise CY-a) for metallocene catalysts too, at least before the downturn. What causes this unexpected response is currently not understood. It is a rare example of higher acidity being associated with decreased long-chain branching.

The influence of sulfate on the Phillips catalyst is remarkable [107]. Table 3 details this very unusual response. With the addition of sulfate, an extreme narrowing of the MW distribution is observed, indicating that the distribution of $\mathrm{Cr}$ environments has become much more homogeneous. This, in turn, affects the other polymer properties, including the rheological parameters. The zero-shear melt viscosity eta(0) and the relaxation time tau-eta are both amazingly low for such high molecular weight polymer. The CY-a parameter, indicating the relaxation time distribution, is far above anything $\mathrm{Cr}(\mathrm{VI})$ / silica has produced. Together, this indicates a polymer of exceptionally low long-chain branching and elasticity. 
Table 3. Response of $\mathrm{Cr}$ /alumina with rising sulfate content.

\begin{tabular}{ccccc}
\hline $\mathrm{SO}_{4} / \mathrm{nm}^{2}$ & 0 & 2.01 & 4.01 & 8.03 \\
HLMI & 4.84 & 3.12 & 2.28 & 0.27 \\
Shear Response & $>200$ & 46.8 & 42.7 & 311 \\
$M_{W}, \mathrm{~kg} / \mathrm{mol}$ & 473 & 339 & 1303 & 379 \\
$M_{Z}, \mathrm{~kg} / \mathrm{mol}$ & 3708 & 1402 & 10.8 & 1595 \\
$M_{W} / M_{N}$ & 99.8 & 13.1 & 4.1 & 10.9 \\
$M_{Z} / M_{W}$ & 7.6 & 4.0 & $5.7 \times 10^{5}$ & $1.4 \times 10^{6}$ \\
Eta(0), Pa-s & $8.1 \times 10^{6}$ & $4.9 \times 10^{5}$ & 2.33 & 5.17 \\
Tau-eta, s & 141 & 2.04 & 0.3014 & 0.3846 \\
CY-a & 0.2749 & 0.2962 & & \\
\hline
\end{tabular}

\subsubsection{The Influence of Adding Phosphate to Alumina}

Adding phosphate to a $\mathrm{Cr}$ /alumina catalyst greatly improves its activity, and it also lowers the polymer $M_{W}[26,108]$, much like adding titania to $\mathrm{Cr} /$ silica does $[109,110]$. LCB formation increases with the addition of phosphate [81]. This is consistent with the general association of LCB with increased acidity, in this case of the Bronsted site population to which Cr must bind.

The activity of metallocene catalysts increased about four-fold when phosphate was added to alumina [83]. Addition of fluoride or sulfate along with the phosphate further increased the activity. The effect of phosphate on metallocene catalysts was not as powerful as its effect on Phillips catalysts. Perhaps this is because the addition of phosphate mainly changes the hydroxyl population on alumina, making it more acidic. In contrast, metallocene catalyst activity is increased by enhancement in the Lewis acidity of the support.

\subsubsection{The Influence of Calcination Temperature on Activity and LCB Formation}

For Phillips catalysts, the calcination temperature is one of the most powerful variables in determining activity $[3,21,110]$. In addition to oxidizing the $\mathrm{Cr}[111]$, high temperatures are thought to remove $\mathrm{OH}$ ligands, and add stress to the -O-Cr-O- bonds as illustrated in Scheme 1. With silica as the support, the activity first develops after calcination at about $400{ }^{\circ} \mathrm{C}$, and it continues to rise up to the point of sintering, usual around $900{ }^{\circ} \mathrm{C}$. Other supports also tend to follow this trend, although the activity can vary widely. For example, the activity of $\mathrm{Cr}$ /alumina rises with calcination temperature, but for a given temperature it never reaches the activity of $\mathrm{Cr} /$ silica. High calcination temperatures tend to favor LCB formation from both supports $[3,21,79]$.

The metallocene catalysts are also sensitive to the calcination temperature. Figure 12 shows two examples of this. It plots the activity of metallocene $C$ on fluorided silicaalumina (Figure 12A) and also on sulfated alumina (Figure 12B), both after calcination at various temperatures. Notice that in both plots the activity rises from about $300{ }^{\circ} \mathrm{C}$ up to about $500{ }^{\circ} \mathrm{C}$ and then it levels off up to $700^{\circ} \mathrm{C}$, which is nearing the point of sintering. Like the Phillips catalysts, LCB formation by the metallocene catalysts in Figure 12 increased with rising temperature. This is shown by the decreasing CY-a parameter in Figure 12. 


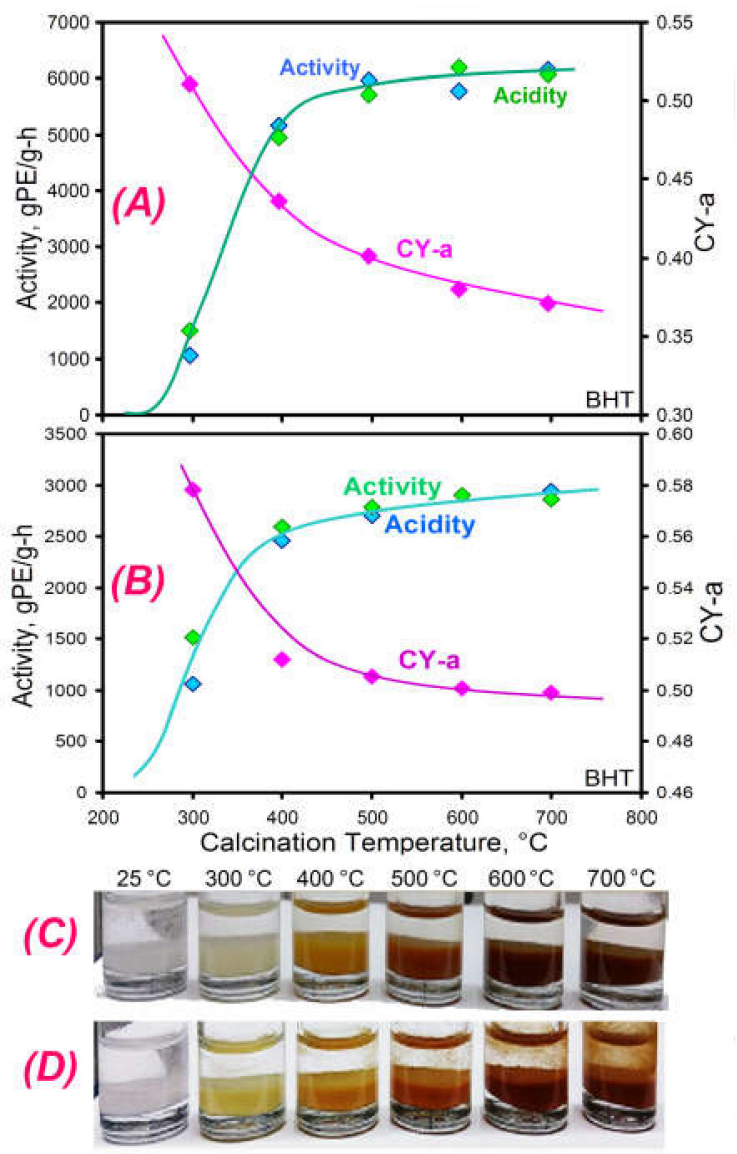

Figure 12. Activity, acidity and LCB (CY-a) from metallocene C supported on (A) fluorided silicaalumina, or (B) sulfated alumina, and colors (C) and (D) obtained respectively with BHT, all as a function of calcination temperature.

At the bottom of Figure 12 are the colors developed by one of the many indicators tested (BHT) when exposed to these samples. The color intensity is plotted under the title "acidity." Using the $25{ }^{\circ} \mathrm{C}$ sample as the zero mark, notice that for both supports the color intensity parallels the activity quite nicely. Of course, this reaction does not distinguish between Bronsted and Lewis activity.

\subsubsection{The Influence of Adding Sodium on Activity and LCB Formation}

It was found that the acidity of the support could usually be neutralized by the addition of a small amount of sodium to the support prior to calcination. This is shown in Figure 13A,B for metallocene $C$ on two series of solid acids, fluorided silica-alumina and sulfated alumina. As the amount of sodium on the support increased, the activity dropped for both supports. LCB formation also declined as indicated directly in 13A, and by the rising CY-a in 13B. 

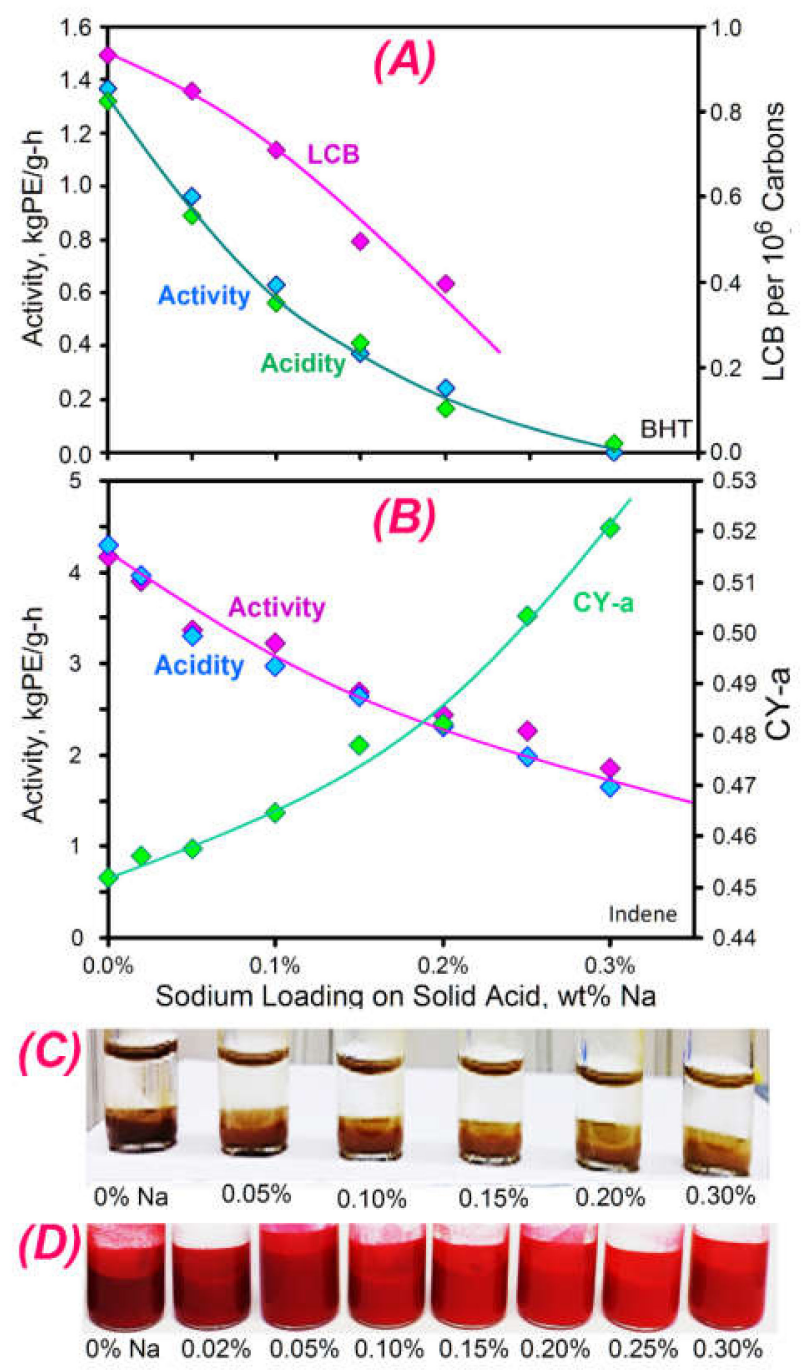

Figure 13. The effect of doping solid acids with sodium: (A) and (C) fluorided silica-alumina, (B) and (D) sulfated alumina. Colors show reaction with BHT (C) and indene (D).

At the bottom in Figure 13C,D are the colors developed upon exposure of fluorided silica-alumina samples to BHT (13C) and the sulfated alumina samples to indene (13D). Other indicators also worked for this purpose. The intensity of the color is plotted in the graphs above under the title of "acidity." Notice that, in both cases, the "acidity," or color intensity, parallels the polymerization activity.

\subsubsection{The Influence of Other Promoters on Activity and LCB Formation}

In other experiments various other promoters were added to alumina or to silicaalumina to increase the acidity. Once promoted with another ion, these supports were converted into a Phillips catalyst, by adding $\mathrm{Cr}$ and then calcining. They were also converted into a metallocene catalyst by calcination of the support followed by impregnation of the metallocene, as indicated. The results of these tests are listed in Table 4. 
Table 4. The effect of other promoters that are known to increase acidity, on the polymerization activity of Phillips and metallocene catalysts.

\begin{tabular}{|c|c|c|c|c|c|c|}
\hline \multirow[b]{2}{*}{ Promoter } & \multirow[b]{2}{*}{ Amount } & \multirow[b]{2}{*}{$\begin{array}{l}\text { Support } \\
\text { Type }\end{array}$} & \multirow[b]{2}{*}{$\begin{array}{c}\text { Calcination } \\
\text { Temp. }\end{array}$} & \multicolumn{2}{|c|}{ Metallocene } & \multirow{2}{*}{$\begin{array}{l}\text { Phillips } \\
\text { Activity } \\
\text { gPE/g/h }\end{array}$} \\
\hline & & & & Met. type & $\begin{array}{l}\text { Activity } \\
\text { gPE/g/h }\end{array}$ & \\
\hline None & $0 \mathrm{mmol} / \mathrm{g}$ & Alumina & $600{ }^{\circ} \mathrm{C}$ & $\mathrm{C}$ & 92 & 274 \\
\hline Boria & $3.0 \mathrm{mmol} / \mathrm{g}$ & Alumina & $600{ }^{\circ} \mathrm{C}$ & $\mathrm{C}$ & 760 & 5495 \\
\hline Chloride & $0.10 \mathrm{~mol} / \mathrm{g}$ & Alumina & $600{ }^{\circ} \mathrm{C}$ & $\mathrm{C}$ & 339 & 282 \\
\hline Silica & $10 \mathrm{wt} \%$ & Alumina & $600{ }^{\circ} \mathrm{C}$ & $\mathrm{C}$ & 2820 & 984 \\
\hline Zinc & $1.5 \mathrm{mmol} / \mathrm{g}$ & Alumina & $600^{\circ} \mathrm{C}$ & $\mathrm{C}$ & 3294 & 466 \\
\hline None & $0 \mathrm{mmol} / \mathrm{g}$ & $\begin{array}{c}\mathrm{Si}^{-} \\
\text {Alumina }\end{array}$ & $600^{\circ} \mathrm{C}$ & $\mathrm{C}$ & 591 & 1882 \\
\hline Boria & $3.0 \mathrm{mmol} / \mathrm{g}$ & $\begin{array}{c}\text { Si- } \\
\text { Alumina }\end{array}$ & $600^{\circ} \mathrm{C}$ & $\mathrm{C}$ & 1320 & 2020 \\
\hline None & $0 \mathrm{mmol} / \mathrm{g}$ & $\begin{array}{c}\mathrm{Cl}- \\
\text { Alumina }\end{array}$ & $600^{\circ} \mathrm{C}$ & A & 2800 & 282 \\
\hline Tin & $2.0 \mathrm{mmol} / \mathrm{g}$ & $\begin{array}{c}\mathrm{Cl}^{-} \\
\text {Alumina }\end{array}$ & $600^{\circ} \mathrm{C}$ & A & 6859 & 533 \\
\hline Zinc & $1.5 \mathrm{mmol} / \mathrm{g}$ & $\begin{array}{c}\mathrm{Cl}^{-} \\
\text {Alumina }\end{array}$ & $600^{\circ} \mathrm{C}$ & A & 14,000 & 466 \\
\hline
\end{tabular}

For example, consider the second row in Table 4. An alumina support was treated with boria and then calcined at $600{ }^{\circ} \mathrm{C}$. This increased the activity of the metallocene catalyst from $92 \mathrm{~g} / \mathrm{g} / \mathrm{h}$ for $\mathrm{Cr} /$ alumina, up to $760 \mathrm{~g} / \mathrm{g} / \mathrm{h}$, which is about an eight-fold rise. It also increased the Phillips catalyst activity from 274 up to $5495 \mathrm{~g} / \mathrm{g} / \mathrm{h}$, which is a 20-fold rise. Going further down Table 4 we see that adding chloride, much like fluoride [112], mainly increases Lewis acidity, resulting in a three-fold rise in metallocene activity, but hardly any change in Phillips activity. This is another indication that Bronsted acidity is important for Phillips catalysts, and Lewis acidity for metallocene catalysts. Adding silica to the alumina base greatly increased the metallocene activity as did zinc. But these two promoters were not quite as impressive for the Phillips catalyst. Thus, all of these promoters were effective, but some were more remarkable than others. That a promoter worked better for Phillips catalyst than for metallocene, or vice versa, can be interpreted by its embellishment of Bronsted vs. Lewis acidity.

\section{Discussion}

Phillips and metallocene catalysts have similar responses to a number of common supports. Some of these, like the dependence of activity on the support porosity, is understandable. Other variables, however, are more difficult to comprehend, such as the similar dependence of turnover on metal loading. Likewise, both catalysts exhibit enhanced LCB formation at the start of a polymerization. The first polymer produced, prior to fragmentation, is made entirely inside pores, and we speculated that sites inside crowded pores retain macromer more effectively, thus producing higher LCB.

The other obvious commonality between Phillips and metallocene catalysts is the role of acidity. The most acidic supports seemed to yield the highest activity and the most LCB. The one glaring exception is the high activity of $\mathrm{Cr}$ on silica, which is not particularly acidic. In this case, however, electron deficiency is thought to be created by strain generated during the annealing process. Phillips catalysts benefit from Bronsted acidity whereas metallocenes seem mainly activated by Lewis sites. This explains some of the differences observed between Phillips and metallocene catalyst response to various supports. However, most of the supports we tested contained both types of acidity.

Understanding the role of acidity also helps to explain why poisons (Lewis bases) and sodium tend to suppress not only activity, but also LCB formation and comonomer incorporation.

In these studies, we have not said much about the molecular weight of the polymer. The molecular weight from metallocene catalysts seemed to be relatively constant even 
from quite different supports. This is probably due to the formation of an ion pair, in which the $\mathrm{Zr}$ is not directly attached to the support. Instead, the molecular weight from these metallocene catalysts seemed to be influenced mostly from the steric environment dictated by the rings ligated to the Zr. In contrast, the molecular weight from Phillips catalysts varied significantly with the choice of support. Being directly attached to the surface, Cr probably feels the electron pull of acidic sites, and is also influenced by the degree of ligation from surface hydroxyls or oxide neighbors.

\section{Materials and Methods}

\subsection{Catalyst Preparation}

Alumina used in this study was obtained from W.R. Grace (Baltimore, MD, USA) under the name Alumina A. It had a surface area of $300 \mathrm{~m}^{2} / \mathrm{g}$, a pore volume of $1.3 \mathrm{~mL} / \mathrm{g}$, and an average particle size of about $80 \mu \mathrm{m}$. To sulfate the support, it was first calcined at $600{ }^{\circ} \mathrm{C}$, then impregnated with an aqueous solution of sulfuric acid. Finally, it was dried and calcined again at $600{ }^{\circ} \mathrm{C}$.

Silica-alumina was also obtained from W.R. Grace as MS13-110. It had a surface area of $450 \mathrm{~m}^{2} / \mathrm{g}$, a pore volume of $1.2 \mathrm{~mL} / \mathrm{g}$, and an average particle size of $100 \mu \mathrm{m}$. To fluoride the support, it was impregnated with an aqueous solution of ammonium bifluoride, then dried and calcined at $450{ }^{\circ} \mathrm{C}$.

Chromium catalysts were made by impregnating these supports, prior to calcination, with a methanol solution of chromium acetate [111,113]. Then they were dried in a vacuum oven, followed by calcination as indicated. The $\mathrm{Cr}$ / silica-titania catalyst used herein was prepared according to Dietz [39]. It had a surface area of $500 \mathrm{~m}^{2} / \mathrm{g}$, a pore volume of $2.6 \mathrm{~mL} / \mathrm{g}$, and an average particle size of $130 \mu \mathrm{m}$.

\subsection{Calcination}

Calcination of the catalyst was accomplished in a $4.75 \mathrm{~cm}$ diameter vertical quartz tube. Dry air was passed up through a sintered quartz disk which supported the fluidized catalyst bed. The air had a linear velocity of $1.5 \mathrm{~cm} / \mathrm{s}$ to fluidize the catalyst. The air and nitrogen used in this study were dried by passage through a $13 \times$ molecular sieve column. The catalyst bed was then heated at the rate of $400{ }^{\circ} \mathrm{C} / \mathrm{h}$ to the indicated temperature, as indicated, at which point it was fluidized while still in dry air for another three hours. This method is known to oxidize and bind the $\mathrm{Cr} /$ silica onto the surface almost quantitatively as chromate or dichromate esters [40,41]. Finally, the catalyst was cooled to $25^{\circ} \mathrm{C}$ while fluidizing in dry air, and then the air was flushed out by dry nitrogen for $30 \mathrm{~min}$, followed by discharge and capture under nitrogen. At no time after calcination was the catalyst exposed to the atmosphere. Solid acids were calcined using the same procedure.

\subsection{Polymerization}

After calcination of the Phillips catalyst, it was then tested for polymerization activity. Polymerization runs were made in a $2.2 \mathrm{~L}$ steel reactor equipped with a marine stirrer rotating at $500 \mathrm{rpm}$. The reactor was surrounded by a steel jacket through which was passed a mixture of steam and water, which was adjusted to maintain a constant temperature of $105^{\circ} \mathrm{C} \pm 0.5^{\circ} \mathrm{C}$, or as indicated, with the help of electronic control instruments.

Unless otherwise stated, a small amount (0.01 to $0.10 \mathrm{~g}$ normally) of the solid catalyst was first charged under nitrogen to the dry reactor. Next $1.2 \mathrm{~L}$ of isobutane liquid was charged to the reactor and it was then heated up to $105^{\circ} \mathrm{C}$. Finally, ethylene was added to the reactor to equal a fixed pressure, normally 3.79 $\mathrm{MPa}$ gauge, which was maintained during the experiment. This is equivalent to about $1.5 \mathrm{~mol}$ ethylene per $\mathrm{L}$ in solution. Stirring was allowed to continue for the specified time, usually around one hour, or until about $3000 \mathrm{~g}$ of PE was produced per gram of catalyst. The instantaneous polymerization rate was noted by recording the flow of ethylene into the reactor to maintain the set pressure.

After the allotted time, the ethylene flow was stopped and the reactor was slowly depressurized and opened to recover a granular polymer powder. In all cases the reactor was 
clean with no indication of any wall scale, coating, or other forms of fouling. The polymer powder was then removed and weighed. The catalyst activity was specified as grams of polymer produced per gram of solid catalyst charged to the reactor per hour. When the generic word "activity" is used in this report, it refers to this number. The "activity" or "catalyst activity" should not be confused with the "turnover frequency" which was used in this report to indicate the number of ethylene molecules consumed per atom of $\mathrm{Cr}$ or $\mathrm{Zr}$ in the reactor per second, as measured over the entire time of the polymerization run. Finally, note also that in Figure 2 the term "yield" is also used, indicating the weight of PE made during the entire time of the polymerization run per gram of solid catalyst, without reference to any unit of time.

Metallocene catalyst polymerizations were carried out like that described above, and also in a one-gallon stirred Autoclave Engineers (Erie, PA, USA) reactor. It had a jacket through which was passed a mixture of water and steam to control temperature to within $\pm 0.5^{\circ} \mathrm{C}$. The reactor was first prepared for use by purging with nitrogen and heating the empty vessel to $120{ }^{\circ} \mathrm{C}$. After cooling to below $40{ }^{\circ} \mathrm{C}$ and purging with isobutane vapor, the reactor was charged with 50 to $100 \mathrm{mg}$ of the solid acid support. Then 0.4 to $0.5 \mathrm{~mL}$ of a $1 \mathrm{M}$ heptane solution of triethylaluminum or triisobutyl aluminum was added. Finally, $0.5-3 \mathrm{~mL}$ of a toluene solution containing $1 \mathrm{mg} / \mathrm{mL}$ of the metallocene compound was charged to the reactor under nitrogen and the reactor was closed. The amount of metallocene charged was chosen based on the previous tests, to be in excess of the support's ability to adsorb it. Thus, in these experiments, with the exception of Figure 2, the ratedetermining ingredient was the solid oxide.

The reactor was subsequently charged with $40 \mathrm{~mL}$ of 1-hexene in some copolymerization experiments, and then two liters of isobutane liquid, followed by heating to $90{ }^{\circ} \mathrm{C}$ or as indicated. The slurry was stirred at $700 \mathrm{rpm}$. Ethylene was then added to the reactor and fed on demand to maintain a fixed total pressure of $2.9 \mathrm{MPa}$. This is again equivalent to about $1.5 \mathrm{~mol}$ ethylene per $\mathrm{L}$. The reactor was maintained at the specified temperature for $30 \mathrm{~min}$. Then the isobutane and ethylene were vented out of the reactor, which was opened, and the polymer was collected usually as a dry powder. Again, in this paper, the "activity" refers to the weight of PE produced over the entire time of the polymerization run, per unit weight of the solid oxide per hour. Metallocene compounds used in this study were as follows:

$$
\begin{aligned}
& \left.\mathrm{A}=(\mathrm{n}-\mathrm{Bu}-\mathrm{Cp})_{2} \mathrm{ZrCl}_{2} ; \mathrm{B}=\text { rac-Et(Ind }\right)_{2} \mathrm{ZrCl}_{2} ; \\
& \mathrm{C}=\mathrm{C}\left(\mathrm{CH}_{3}\right)\left(\mathrm{C}_{4} \mathrm{H}_{7}\right)(\mathrm{di}-\mathrm{t}-\mathrm{Bu}-\mathrm{Flu})(\mathrm{Cp}) \mathrm{ZrCl}_{2} ; \mathrm{D}=\mathrm{C}\left(\mathrm{CH}_{3}\right)\left(\mathrm{C}_{4} \mathrm{H}_{9}\right)(\mathrm{Flu})(\mathrm{Cp}) \mathrm{ZrCl}_{2}
\end{aligned}
$$

\subsection{Rheology}

Rheology measurements were obtained on the polymers as follows: polymer samples were first stabilized with $0.1 \mathrm{wt} \%$ BHT dissolved in acetone, and then they were vacuum dried. Next the sample was compression molded at $182{ }^{\circ} \mathrm{C}$ for a total of three minutes. Each sample was allowed to melt at a relatively low pressure for one minute and then subjected to a high-molding pressure for an additional two minutes. The molded samples were then quenched in a cold (room temperature) press. Disks of $2 \mathrm{~mm}$ thickness by $25.4 \mathrm{~mm}$ diameter were stamped out of the molded slabs for rheological characterization.

Small-strain oscillatory shear measurements were performed on a Rheometrics Inc. RMS-800 (Piscataway, NJ, USA) or ARES rheometer (TA Instruments, New Castle, DE, USA) using parallel-plate geometry over an angular frequency range of 0.03-100 rad/s. The test chamber of the rheometer was blanketed in nitrogen in order to minimize polymer degradation during the test. The rheometer was preheated to the initial temperature of the study. Upon sample loading and after oven thermal equilibration, the specimens were squeezed between the plates to a $1.6 \mathrm{~mm}$ thickness and the excess was trimmed off. A total of about eight minutes elapsed between the time the sample was inserted between the plates and the time the frequency sweep was started. 
The LCB levels in samples were calculated using the method of Janzen and Colby [43] from values of weight-average molecular weight $\left(M_{W}\right)$, and the zero-shear viscosity $(\eta 0)$, which was estimated from the Carreau-Yasuda model.

Strains were generally maintained at a single value throughout a frequency sweep, but larger strain values were used for low viscosity samples to maintain a measurable torque. Smaller strain values were used for high viscosity samples to avoid overloading the torque transducer and to keep within the linear viscoelasitc limits of the sample. The instrument automatically reduced the strain at high frequencies if necessary, to keep from overloading the torque transducer. These data were fit to the Carreau-Yasuda equation to determine zero shear viscosity $(\eta 0)$, relaxation time $(\tau)$, and a measure of the breadth of the relaxation time distribution (CY-a). [42]

\subsection{Molecular Weight}

Molecular weight and molecular weight distribution (MWD) were obtained using a PL 220 GPC/SEC high-temperature chromatography unit (Polymer Laboratories, now an Agilent Company, Santa Clara, CA, USA) with 1,2,4-trichlorobenzene (TCB) as the solvent, with a flow rate of $1.0 \mathrm{~mL} / \mathrm{min}$ at a temperature of $145^{\circ} \mathrm{C}$. BHT (2,6-di-tert-butyl-4methylphenol) at a concentration of $0.5 \mathrm{~g} / \mathrm{L}$ was used as a stabilizer in the TCB. An injection volume of $400 \mu \mathrm{L}$ was used with a nominal polymer concentration of $0.5 \mathrm{mg} / \mathrm{mL}$. Dissolution of the sample in stabilized TCB was carried out by heating at $150{ }^{\circ} \mathrm{C}$ for about $4 \mathrm{~h}$ with occasional, gentle agitation, depending on dissolution temperature and polymer solution. Three Waters Styrogel HMW-6E columns were used and were calibrated with the integral method using a broad linear polyethylene standard (Chevron Phillips Chemicals' Marlex ${ }^{\circledR}$ RTM BHB 5003 polyethylene, Houston, TX, USA) for which the MWD had been determined. An IR4 detector (Polymer Char, Valencia, Spain) was used for the concentration detection.

\subsection{SEC-MALS}

SEC-MALS is a combined method of size-exclusion chromatography (SEC), also known as gel-permeation chromatography (GPC), with multi-angle light scattering (MALS) [44,45]. A DAWN EOS multi-angle light scattering photometer (Wyatt Technology, Santa Barbara, CA, USA) was attached to a Waters $150-\mathrm{CV}$ plus GPC system through a transfer line thermally controlled at $145^{\circ} \mathrm{C}$. At a flow rate of $0.7 \mathrm{~mL} / \mathrm{min}$, the mobile phase 1,2,4-trichlorobenzene (TCB) containing $0.5 \mathrm{~g} / \mathrm{L}$ of 2,6-di-tert-buty-1,4-methylphenol (BHT) was eluted through three $\phi 7.5 \mathrm{~mm} \times 300 \mathrm{~mm} 20 \mu \mathrm{m}$ mixed A-LS columns (Polymer Labs, now a Varian Company, Shropshire, UK). PE solutions with nominal concentrations of $1.0 \mathrm{mg} / \mathrm{mL}$ were prepared at $150{ }^{\circ} \mathrm{C}$ for $3-4 \mathrm{~h}$ before being transferred to SEC injection vials sitting in a carousel heated at $145^{\circ} \mathrm{C}$. In addition to a concentration chromatogram, 17 light scattering chromatograms at different scattering angles were acquired for each injection. At each chromatographic slice, both the absolute molecular weight $(\mathrm{M})$ and the root-mean square radius, commonly known as the radius of gyration, $\mathrm{Rg}$, were obtained from a Debye plot [44]. The linear PE control employed in this study was a high-density polyethylene (HDPE) with a broad molecular weight distribution (MWD), Marlex ${ }^{\circledR}$ 9640. The refractive index increment $\mathrm{dn} / \mathrm{dc}$ used in this study was 0.097 for PE in TCB at $135^{\circ} \mathrm{C}$ [45]. A detailed description of the SEC-MALS method can be found elsewhere [45]. At the run temperature, $145^{\circ} \mathrm{C}$, it was found that $\mathrm{dn} / \mathrm{dc}$ equals to $0.095 \mathrm{~mL} / \mathrm{g}$ by assuming refractive index changes linearly as a function of temperature and the polymer standard is $100 \%$ soluble.

Author Contributions: Conceptualization, investigation, and methodology. Q.Y. and M.P.M. All authors have read and agreed to the published version of the manuscript.

Funding: This research was funded entirely by Chevron Phillips Chemical Co.

Data Availability Statement: The data presented in this study are openly available through the USPTO website https: / / www.USPTO.gov, accessed on 12 July 2021. 
Acknowledgments: The authors wish to thank K.S. Clear and R. Rose for conducting some of the polymerizations listed herein.

Conflicts of Interest: The authors declare no conflict of interest.

\section{References}

1. Hogan, J.P.; Banks, R.L. Polymers and Production Thereof, Belg. Pat. 530,617 (in French) and US 2,825,721 (in English), filed 26 March 1956, issued 4 March 1958.

2. Cossee, P.; Catalysis, Z.-N.I. Mechanism of Polymerization of $\alpha$-olefins with Ziegler-Natta Catalyst. J. Catal. 1964, 3, 80-88. [CrossRef]

3. McDaniel, M.P. Review of the Phillips Polymerization Catalyst for Ethylene Polymerization. Adv. Catal. 2010, 53, 123-606.

4. Groppo, E.; Lamberti, C.; Bordiga, S.; Spoto, A.G.; Zecchina, A. The Structure of Active Centers and the Ethylene Polymerization Mechanism on the $\mathrm{Cr} / \mathrm{SiO}_{2}$ Catalyst: A Frontier for the Characterization Methods. Chem. Rev. 2005, 105, 115-184. [CrossRef]

5. Hogan, J.P. Ethylene polymerization catalysis over chromium oxide. J. Polym. Sci. Part A-1 Polym. Chem. 1970, 8, 2637-2652. [CrossRef]

6. Fubini, B.; Ghiotti, G.; Stradella, L.; Garonne, E.; Morterra, C. The Chemistry of Silica-Supported Cr Ions: Reduced and Oxidized Forms of Chromia/Silica Catalyst by Calorimetry and Ultraviolet-Visible Spectroscopy. Support J. Catal. 1980, 66, 200-213. [CrossRef]

7. Iannibello, A.; Marengo, S.; Tittarelli, P.; Morelli, G.; Zecchina, A. Spectroscopic study of the structure of chromium(VI), molybdenum(VI) and tungsten(VI) oxospecies anchored on aluminium oxide. J. Chem. Soc. Faraday Trans. 1 Phys. Chem. Condens. Phases 1984, 80, 2209-2223. [CrossRef]

8. Groppo, E.; Lamberti, C.; Spoto, G.; Bordiga, S.; Magnacca, G.; Zecchina, A. Tuning the structure, distribution and reactivity of polymerization centres of $\mathrm{Cr}(\mathrm{II}) / \mathrm{SiO}_{2}$ Phillips catalyst by controlled annealing. J. Catal. 2005, 236, 233-244. [CrossRef]

9. Martino, G.A.; Barzan, C.; Piovano, A.; Budnyk, A.; Groppo, E. Tracking the reasons for the peculiarity of $\mathrm{Cr} / \mathrm{Al}_{2} \mathrm{O}_{3}$ catalyst in ethylene polymerization. J. Catal. 2018, 357, 206-212. [CrossRef]

10. Peek, N.M.; Jeffcoat, D.B.; Moisii, C.L.; van de Burgt, S.; Profeta, S.L., Jr.; Stiegman, S.A.E. Do Mono-oxo Sites Exist in Sili-caSupported Cr(VI) Materials? Reassessment of the Resonance Raman Spectra. J. Phys. Chem. C 2018, 122, 4349-4358. [CrossRef]

11. Weckhuysen, B.M.; Wachs, I.E. In Situ Raman Spectroscopy of Supported Chromium Oxide Catalysts: $18 \mathrm{O}_{2}-16 \mathrm{O}_{2}$ Isotopic La-beling Studies. J. Phys. Chem. B 1997, 101, 2793-2796. [CrossRef]

12. Weckhuysen, B.M.; De Ridder, L.M.; Schoonheydt, R.A. A quantitative diffuse reflectance spectroscopy study of supported chromium catalysts. J. Phys. Chem. 1993, 97, 4756-4763. [CrossRef]

13. Weckhuysen, B.M.; Verberckmoes, A.A.; Baets, A.R.; Schoonheydt, R.A. Diffuse Reflectance Spectroscopy of Supported Chromium Oxide Catalysts: A Self-Modeling Mixture Analysis. J. Catal. 1997, 166, 160-171. [CrossRef]

14. Zhong, L.; Liu, Z.; Cheng, R.; Tang, S.; Qiu, P.; He, X.; Terano, M.; Liu, B. Effect of F-modification over Phillips Cr/SiO 2 catalyst for ethylene polymerization. ChemCatChem 2012, 4, 872-881. [CrossRef]

15. Groppo, E.; Martino, G.A.; Piovano, A.; Barzan, C. The Active Sites in the Phillips Catalysts: Origins of a Lively Debate and a Vision for the Future. ACS Catal. 2018, 8, 10846-10863. [CrossRef]

16. Morra, E.; Martino, G.A.; Piovano, A.; Barzan, C.; Groppo, E.; Chiesa, M. In SituX- and Q-Band EPR Investigation of Ethylene Polymerization on $\mathrm{Cr} / \mathrm{SiO}_{2}$ Phillips Catalyst. J. Phys. Chem. C 2018, 122, 21531-21536. [CrossRef]

17. Potter, K.C.; Beckerle, C.W.; Jentoft, F.C.; Schwerdtfeger, E.; McDaniel, M.P. Reduction of the Phillips catalyst by various olefins: Stoichiometry, thermochemistry, reaction products and polymerization activity. J. Catal. 2016, 344, 657-668. [CrossRef]

18. Joseph, J.; Potter, K.C.; Wulfers, M.J.; Schwerdtfeger, E.; McDaniel, M.P.; Jentoft, F.C. Products of the initial reduction of the Phillips catalyst by olefins. J. Catal. 2019, 377, 550-564. [CrossRef]

19. Weckhuysen, B.M.; Schoonheydt, R.A. Olefin polymerization over supported chromium oxide catalysts. Catal. Today 1999, 51, 215-221. [CrossRef]

20. Jongkind, M.K.; Meirer, F.; Bossers, K.W.; Have, I.T.; Ohldag, H.; Watts, B.; van Kessel, T.; Friederichs, N.; Weckhuysen, B.M. Influence of Metal-Alkyls on Early-Stage Ethylene Polymerization over a $\mathrm{Cr} / \mathrm{SiO}_{2}$ Phillips Catalyst: A Bulk Characterization and X-ray Chemical Imaging Study. Chem. A Eur. J. 2021, 27, 1688-1699. [CrossRef] [PubMed]

21. Ferrari, A.; Garrone, E.; Spoto, G.; Ugliengo, P.; Zecchina, A. Reactions of silica strained rings: An experimental and ab-initio study. Surf. Sci. 1995, 323, 151-162. [CrossRef]

22. McDaniel, M.P.; Welch, M.B. The Activation of the Phillips Polymerization Catalyst, 1. Influence of the OH Population. J. Catal. 1983, 82, 98-109. [CrossRef]

23. Groppo, E.; Damin, A.; Bonino, F.; Zecchina, A.; Bordiga, S.; Lamberti, C. New Strategies in the Raman Study of the $\mathrm{Cr} / \mathrm{SiO}_{2}$ Phillips Catalyst: Observation of Molecular Adducts on $\mathrm{Cr}$ (II) Sites. Chem. Mater. 2005, 17, 2019-2027. [CrossRef]

24. Demmelmaier, C.A.; White, R.E.; Van Bokhoven, J.A.; Scott, S.L. Evidence for a chromasiloxane ring size effect in Phillips $\left(\mathrm{Cr} / \mathrm{SiO}_{2}\right)$ polymerization catalysts. J. Catal. 2009, 262, 44-56. [CrossRef]

25. Welch, M.; McDaniel, M. The activation of the Phillips polymerization catalyst II. Activation by reduction/reoxidation. J. Catal. 1983, 82, 110-117. [CrossRef]

26. McDaniel, M.P.; Johnson, M.M. A comparison of $\mathrm{Cr} / \mathrm{SiO}_{2}$ and $\mathrm{Cr} / \mathrm{AlPO}_{4}$ polymerization catalysts. 2. Chain transfer. Macromolecules 1987, 20,773-778. [CrossRef] 
27. McDaniel, M.P.; Leigh, C.H.; Wharry, S.M. Ethylene Polymerization from Supported Organotransition Metal Complexes, III. Support Interactions. J. Catal. 1989, 120, 170-181. [CrossRef]

28. Zecchina, A.; Groppo, E. Surface chromium single sites: Open problems and recent advances. Proc. R. Soc. A Math. Phys. Eng. Sci. 2012, 468, 2087-2098. [CrossRef]

29. Smith, P.D.; McDaniel, M.P. Ethylene Polymerization from Supported Organotransition Metal Complexes, II Chromium Al-kyls. J. Polym. Sci. Part A Polymer Chem. 1990, 28, 3587-3601. [CrossRef]

30. Bordiga, S.; Barzan, C.; Damin, A.A.; Budnyk, A.; Zecchina, A.; Groppo, E. Pre-reduction of the Phillips CrVI/SiO2 catalyst by cyclohexene: A model for the induction period of ethylene polymerization. J. Catal. 2017, 337, 45-51.

31. Smith, P.D.; McDaniel, M.P. Ethylene Polymerization from Supported Organotransition Metal Complexes, I. Pentadienyl Derivatives of Ti, V and Cr. J. Polym. Sci. Part A Polym. Chem. 1989, 27, 2695-2710. [CrossRef]

32. Zheng, X.X.; Smit, M.M.; Chadwick, J.C.; Loos, J.J. Fragmentation Behavior of Silica-Supported Metallocene/MAO Catalyst in the Early Stages of Olefin Polymerization. Macromolecules 2005, 38, 4673-4678. [CrossRef]

33. Kaminsky, W. The discovery of metallocene catalysts and their present state of the art. J. Polym. Sci. Part A Polym. Chem. 2004, 42, 3911-3921. [CrossRef]

34. Charoenchaidet, S.; Chavadej, S.; Gulari, E. Borane-functionalized silica supports: In situ activated heterogeneous zirconocene catalysts for MAO-free ethylene polymerization. J. Mol. Catal. A: Chem. 2002, 185, 167-177. [CrossRef]

35. Welch, M.B.; Palackal, S.J.; Hauger, B.E.; Dockter, D.W.; Koppl, A.; Alt, H.G. Metallocenes, polymerization catalyst systems, their preparation, and use. U.S. Patent 6,992,035, 31 January 2006.

36. Welborn, H.C.; Ewen, J.A., Jr. Metallocene Catalysts using MAO. U.S. Patent 5,324,800, 28 June 1994.

37. McDaniel, M.P.; Jensen, M.D.; Jayaratne, K.; Collins, K.S.; Benham, E.A.; McDaniel, N.D.; Das, P.K.; Martin, J.L.; Yang, Q.; Thorn, M.G.; et al. Metallocene Activation by Solid Acids. Tailor-Made Polym. 2008, 171-210. [CrossRef]

38. Jenxen, M.D.; Hain, J.; Myers, A. What is driving change in polyolefin catalyst technology. Hydrocarb. Process. 2008, 1-3.

39. Dietz, R.E. Silica-Titania Cogel Catalyst. U.S. Patent 3,119,569, 3 June 1975.

40. McDaniel, M. The state of $\mathrm{Cr}(\mathrm{VI})$ on the Phillips polymerization catalyst IV. Saturation coverage. J. Catal. 1982, 76, 37-47. [CrossRef]

41. Weckhuysen, B.M.; Wachs, A.I.E.; Schoonheydt, R.A. Surface Chemistry and Spectroscopy of Chromium in Inorganic Oxides. Chem. Rev. 1996, 96, 3327-3350. [CrossRef]

42. Bird, R.B.; Armstrong, R.C.; Hassager, O. Dynamics of Polymeric Liquids Fluid Mechanics; John Wiley \& Sons: New York, NY, USA, 1987; Volume 1.

43. Janzen, J.; Colby, R. Diagnosing long-chain branching in polyethylenes. J. Mol. Struct. 1999, 485-486, 569-583. [CrossRef]

44. Wyatt, P.J. Light scattering and the absolute characterization of macromolecules. Anal. Chim. Acta 1993, 272, 1-40. [CrossRef]

45. Yu, Y.; DesLauriers, P.J.; Rohlfing, D.C. SEC-MALS method for the determination of long-chain branching and long-chain branching distribution in polyethylene. Polymer 2005, 46, 5165-5182. [CrossRef]

46. Cavallo, L.; Fait, A.; Piemontesi, F. Selectivity in Propene Polymerization with Metallocene Catalysts. Chem. Rev. 2000, 100, 1253-1346.

47. Zaccaria, F.; Ehm, C.; Budzelaar, P.H.M.; Busico, V. Accurate Prediction of Copolymerization Statistics in Molecular Olefin Polymerization Catalysis: The Role of Entropic, Electronic, and Steric Effects in Catalyst Comonomer Affinity. ACS Catal. 2017, 7, 1512-1519. [CrossRef]

48. Ehm, C.; Vittoria, A.; Goryunov, G.P.; Kulyabin, P.S.; Budzelaar, P.H.M.; Voskoboynikov, A.Z.; Busico, V.; Uborsky, D.V.; Cipullo, R. Connection of Stereoselectivity, Regioselectivity, and Molecular Weight Capability in rac-R'2Si(2-Me-4-R-indenyl)2ZrCl2 Type Catalysts. Macromolecules 2018, 51, 8073-8083. [CrossRef]

49. Kulyabin, P.S.; Goryunov, G.P.; Sharikov, M.I.; Izmer, V.V.; Vittoria, A.; Budzelaar, P.H.; Busico, M.V.; Voskoboynikov, A.Z.; Ehm, C.; Cipullo, R.; et al. Ansa-Zirconocene Catalysts for Isotactic-Selective Propene Polymerization at High Temperature: A Long Story Finds a Happy Ending. J. Am. Chem. Soc. 2021, 143, 7641-7647. [CrossRef]

50. Brintzinger, H.H.; Fischer, D.R.; Rieger, M.B.; Waymouth, R.M. Stereospecific Olefin Polymerization with Chiral Metallocene Catalysts Angew. Chem. Int. Ed. 1995, 34, 1143-1170. [CrossRef]

51. Röll, W.; Brintzinger, H.H.; Rieger, B.; Stero, R.Z. Regioselectivity of Chiral, Alkyl-substituted ansa-Zirconece Catalysts in Methylalumoxane-activator Propene Polymerization Angew. Chem. Int. Ed. 1990, 3, 279-280. [CrossRef]

52. Uborsky, D.V.; Mladentsev, D.Y.; Guzeev, B.A.; Borisov, I.S.; Vittoria, A.; Ehm, C.; Cipullo, R.; Hendriksen, C.; Busico, N.F.V.; Voskoboynikov, A.Z. C1-Symmetric Si-bridged (2-indenyl)(1-indenyl) ansa-metallocenes as efficient eth-ene/1-hexene copolymerization catalysts. Dalton Trans. 2020, 49, 3015-3025. [CrossRef] [PubMed]

53. Ehm, C.; Vittoria, A.; Goryunov, G.P.; Izmer, V.V.; Kononovich, D.S.; Samsonov, O.V.; Budzelaar, P.H.M.; Voskoboynikov, A.Z.; Busico, V.; Uborsky, D.V.; et al. On the limits of tuning comonomer affinity of 'Spaleck-type' ansa-zirconocenes in ethene/1-hexene copolymerization: A high-throughput experimentation/QSAR approach. Dalton Trans. 2020, 49, 10162-10172. [CrossRef]

54. Yang, Q.; Jensen, M.D.; McDaniel, M.P. Alternative View of Long Chain Branch Formation by Metallocene Catalysts. Macromolecules 2010, 43, 8836-8852. [CrossRef]

55. DesLauriers, P.J.; McDaniel, M.P. Short chain branching profiles in polyethylene from the Phillips Cr/silica catalyst. J. Polym. Sci. Part A: Polym. Chem. 2007, 45, 3135-3149. [CrossRef]

56. McDaniel, M.P.; Martin, S.J. Poisoning Studies on Cr/Silica, Carbon Monoxide. J. Phys. Chem. 1991, 95, 3289-3293. [CrossRef] 
57. Zecchina, A.; Garroñe, E.; Ghiotti, G.; Coluccia, S. On the Chemistry of Silica-Supported Chromium Ions, One-Ligand Complexes, Adsorption of Carbon Monoxide, Carbon Dioxide and Pyridine. J. Phys. Chem. 1975, 79, 972-978. [CrossRef]

58. Cotes, M.P.; Jordan, R.E. Cationic Aluminum Alkyl Complexes Incorporating Amidinate Ligands. J. Am. Chem. Soc. 1997, 119, 8125-8216.

59. Crowther, D.J.; Borkowsky, S.L.; Swenson, D.; Meyer, T.Y.; Jordan, R.F. Coordination of CB11H12 to cationic zirconium(IV) complexes. Organometallics 1993, 12, 2897-2903. [CrossRef]

60. Baldwin, S.M.; Bercaw, J.E.; Brintzinger, H.H. Cationic Alkylaluminum-Complexed Zirconocene Hydrides as Participants in Olefin Polymerization Catalysis. J. Am. Chem. Soc. 2010, 132, 13969-13971. [CrossRef] [PubMed]

61. Herwig, J.; Kaminsky, W. Halogen-Free Soluble Ziegler Catalysts with MAO as Catalyst. Polym. Bull. 1983, 9, 464-469.

62. Ballard, D.G.H.; Jones, E.; Padget, J.C.; Pioli, A.J.P.; Walker, A.R.J.; Wyatt, R.J. Polymerization Process. U.S. Patent 4,056,669, 1 November 1977.

63. Ahn, H.; Nicholas, C.P.; Marks, T.J. Surface Organozirconium Electrophiles Activated by Chemisorption on "Super Acidic" Sulfated Zirconia as Hydrogenation and Polymerization Catalysts. A Synthetic, Structural, and Mechanistic Catalytic Study. Organometallics 2002, 21, 1788-1806. [CrossRef]

64. McDaniel, M.P.; Short, J.N. Catalyst Comprising Phosphate and Chromocene. U.S. Patent 4,424,139, 3 January 1984.

65. Freeman, J.W.; Wilson, D.R.; Ernst, R.D.; Smith, P.D.; Klendworth, D.D.; McDaniel, M.P. Ethylene polymerization over organochromium catalysts: A comparison between closed and open pentadienyl ligands. J. Polym. Sci. Part A Polym. Chem. 1987, 25, 2063-2075. [CrossRef]

66. Martino, G.A.; Piovano, A.; Barzan, C.; Liao, Y.K.; Morra, E.; Hirokane, K.; Chiesa, M.; Monoi, T.; Groppo, E. Cr[CH(SiMe 3$\left.)_{2}\right]_{3} / \mathrm{SiO}_{2}$ catalysts for ethene polymerization: The correlation at a molecular level between the chromium loading and the microstructure of the produced polymer. J. Catal. 2021, 394, 131-141. [CrossRef]

67. Smith, P.D. Polychromium Compounds. U.S. Patent 4,668,808, 26 May 1987.

68. Walker, D.W.; Czenkusch, E.L. Polymerization Process using Supported Diarene Catalysts. U.S. Patent 3,157,712, 17 November 1964.

69. McDaniel, M.P.; Johnson, M.M. Phosphate Containing Zerovalent Chromium. U.S. Patent 4,364,841, 21 December 1982.

70. McDaniel, M.P.; Smith, P.D. Polymerization Catalyst, Method of Making and use Therefor. U.S. Patent 4,619,980, 28 October 1986.

71. McDaniel, M.P.; Johnson, M.M. Chromium on Mixed Metal Phosphate base with Organoboron Cocatalyst. U.S. Patent 4,481,302, 6 November 1984.

72. McDaniel, M.P.; Smith, P.D.; Norwood, D.D. Silicon and Fluorine-Treated Alumina Containing a Chromium Catalyst and method of Producing Same. U.S. Patent 4,806,513, 21 February 1989.

73. Vuurman, M.A.; Hardcastle, F.D.; Wachs, I.E. Characterization of $\mathrm{CrO}_{3} / \mathrm{Al}_{2} \mathrm{O}_{3}$ Catalysts Under Ambient Conditions. J. Molec. Catal. 1993, 84, 193-205. [CrossRef]

74. McDaniel, M.P.; Benham, E.A.; Martin, S.J.; Collins, K.S.; Smith, J.L.; Hawley, G.R.; Wittner, C.E.; Jensen, M.D. Compositions That Can Produce Polymers. U.S. Patent 6,300,271, 9 October 2001.

75. McDaniel, M.; Welch, M.; Dreiling, M. The activation of the Phillips polymerization catalyst III. Promotion by titania. J. Catal. 1983, 82, 118-126. [CrossRef]

76. McDaniel, M.P.; Collins, K.S.; Smith, J.L.; Benham, E.A.; Johnson, M.M.; Eaton, A.P.; Jensen, M.D.; Martin, J.L.; Hawley, G.R. Organometal catalyst compositions. U.S. Patent 6,395,666, 28 May 2002.

77. McDaniel, M.P.; Collins, K.S. Methods of Preparing a Polymerization Catalyst. U.S. Patent 7,638,456, 29 December 2009.

78. McDaniel, M.P.; Johnson, M.M. Polymerization process using phosphate supported chromium catalyst. U.S. Patent 4,444,964, 24 April 1984.

79. McDaniel, M.P.; Rohlfing, D.C.; Benham, E.A. Long Chain Branching in Polyethylene from the Phillips Chromium Catalyst. Polym. React. Eng. 2003, 11, 101-132. [CrossRef]

80. Yu, Y.; Schwerdtfeger, E.D.; McDaniel, M.P. Size-Exclusion Chromatography Coupled to Multiangle Light Scattering Detec-tion of Long-Chain Branching in Polyethylene Made with Phillips Catalyst. J. Polym. Sci., A. Polym. Chem. 2012, 50, 1166-1173. [CrossRef]

81. DesLauriers, P.J.; Tso, C.; Yu, Y.; Rohlfing, D.L.; McDaniel, M.P. Long-chain branching in PE from Cr/aluminophosphate cata-lysts. Appl. Catal. A: Gen. 2010, 388, 102-112. [CrossRef]

82. Schwerdtfeger, E.D.; Jensen, M.D.; Yang, Q.; McDaniel, M.P. Controlling Long-Chain Branch Formation in Polyethylene. Curr. Topics Catal. 2016, 12, 1-27.

83. McDaniel, M.P.; Benham, E.A.; Collins, K.S.; Smith, J.L.; Hawlely, G.R.; Wittner, C.E.; Jensen, M.D. Process for Producing Polymers. U.S. Patent 6,831,141, 9 October 2001.

84. McDaniel, M.P.; Collins, K.S. Methods of Preparing a Polymerization Catalyst. U.S. Patent 9,068,027, 30 June 2015.

85. McDaniel, M.P.; Collins, K.S. Ethylene polymerization by $\mathrm{Cr}(\mathrm{III})$ salts on acidic carriers. Appl. Catal. A Gen. 2016, 527, 116-126. [CrossRef]

86. McDaniel, M.P. Influence of Catalyst Porosity on Ethylene Polymerization. ACS Catal. 2011, 1, 1394-1407. [CrossRef]

87. McDaniel, M.P. Influence of porosity on PE molecular weight from the Phillips Cr/silica catalyst. J. Catal. 2009, 261, 34-49. [CrossRef]

88. McDaniel, M.P.; Collins, K.S. The influence of porosity on the Phillips Cr/silica catalyst 2. Polyethylene elasticity. J. Polym. Sci. Part A Polym. Chem. 2008, 47, 845-865. [CrossRef] 
89. McDaniel, M.P.; Kelly, S.L. Reinforcement of Cr/silica catalysts by secondary deposition of silicate oligomers. Appl. Catal. A Gen. 2018, 554, 88-94. [CrossRef]

90. Alt, H.G. The heterogenization of homogeneous metallocene catalysts for olefin polymerization. J. Chem. Soc. Dalton Trans. 1999, 1703-1710. [CrossRef]

91. Jensen, M.D.; Yang, Q.; Yu, Y.; McDaniel, M.P. Kinetics of Long-Chain Branch Formation in Polyethylene. ACS Catal. 2017, 8, 725-737. [CrossRef]

92. Monwar, M.M.; Cruz, C.A.; Barr, J.L.; McDaniel, M.P. Ethylene polymerization by hydrocarbon-reduced Cr/silica catalyst. J. Catal. 2021, 394, 451-464. [CrossRef]

93. Groppo, E. Acidic Properties of $\gamma$-Al2O3 and Sulfated Al2O3 Investigated by FT-IR Spectroscopy of Molecular Probes. 2016; in press, unpublished.

94. Hammett, L.P.; Deyrup, A.J. A Series of Simple Basic Indicators. I. the Acidity Functions of Mixtures of Sulfuric and Perchloric Acids with Water1. J. Am. Chem. Soc. 1932, 54, 2721-2739. [CrossRef]

95. Walling, C. The Acid Strength of Surfaces. J. Am. Chem. Soc. 1950, 72, 1164-1168. [CrossRef]

96. Benesi, H.A. Acidity of Catalyst Surfaces. II. Amine Titration Using Hammett Indicators. J. Phys. Chem. 1957, 61, 970-973. [CrossRef]

97. Johnson, O. Acidity and Polymerization Activity of Solid Acid Catalysts. J. Phys. Chem. 1955, 59, 827-831. [CrossRef]

98. Kladnig, W.F. Use of Hammcatt Indicators for Acidity Measurements in Zeolites. J. Phys. Chem. 1979, 83, 765-766. [CrossRef]

99. Alemdaroğlu, T. Determination methods for the acidity of solid surfaces. Commun. Fac. Sci. Univ. Ank. Ser. B Chem. Chem. Eng. 2001, 47, 027-035. [CrossRef]

100. Gold, V.; Hawes, B.W.V. The Ionization of Triarylcarbinols in Strong Acids and the Definition of a New Acidity Function. J. Chem. Soc. 1951, 465, 2102-2111. [CrossRef]

101. Deno, N.C.; Jaruzelski, J.J.; Schriesheim, A. Carbonium Ions. I. An Acidity Function (C0) Derived from Arylcarbonium Ion Equilibria1. J. Am. Chem. Soc. 1955, 77, 3044-3051. [CrossRef]

102. Liu, X.; Iu, K.-K.; Thomas, J.K.; He, H.; Klinowski, J. Spectroscopic Studies of Protonated Aromatic Species and Radical Cations in H+-Zeolites. J. Am. Chem. Soc. 1994, 116, 11811-11818. [CrossRef]

103. Hogan, J.P. Ethylene Homopolymer and Copolymer Polymerization Process and the Products Produced Therefrom. U.S. Patent 5,155,186, 13 October 1992.

104. Amercan Society for Testing and Materials (ASTM). Procedure D1238-E, condition 190/2, at 190 C. with a 2,160 gram weight.

105. Grayson, M.; McDaniel, M. Sulfide poisoning of ethylene polymerization over Phillips Cr/silica catalyst. J. Mol. Catal. 1991, 65, 139-144. [CrossRef]

106. McDaniel, M.P.; Collins, K.S.; Benham, E.A.; Jensen, M.D.; Martin, J.L.; Hawley, G.R. Organometal Catalyst Compositions. U.S. Patent 6,613,852, 2 September 2003.

107. McDaniel, M.P.; Collins, K.S.; Benham, E.A.; Deslauriers, P.J. Methods of Preparing Active Chromium/Alumina Catalysts via Treatment with Sulfate. U.S. Patent 7,214,642, 8 May 2007.

108. McDaniel, M.; Johnson, M. A comparison of $\mathrm{Cr} / \mathrm{SiO}_{2}$ and $\mathrm{Cr} / \mathrm{AlPO} 4$ polymerization catalysts I. Kinetics. J. Catal. 1986, 101, 446-457. [CrossRef]

109. Cheng, R.; Xu, C.; Liu, Z.; Dong, Q.; He, X.; Fang, Y.; Terano, M.; Hu, Y.; Pullukat, T.J.; Liu, B. High-resolution spectroscopy (XPS, 1H MAS solid-state NMR) and DFT investigations into Ti-modified Phillips CrOx/ $\mathrm{SiO}_{2}$ catalysts. J. Catal. 2010, 273, 103-115. [CrossRef]

110. McDaniel, M. The state of $\mathrm{Cr}(\mathrm{VI})$ on the Cr/Silica polymerization catalyst. J. Catal. 1981, 67, 71-76. [CrossRef]

111. Qiu, P.; Li, X.; Zhang, S.; Cheng, R.; Dong, Q.; Liu, B.; Li, L.; Yu, Y.; Tang, Y.; Xie, J.; et al. Supporting mechanism of non-toxic chromium (III) acetate on silica for preparation of Phillips ethylene polymerization catalysts. Asia-Pacific J. Chem. Eng. 2009, 4, 660-665. [CrossRef]

112. Sun, Q.; Cheng, R.; Liu, Z.; He, X.; Zhao, N.; Liu, B. Effect of Fluoride-Modification on the Phillips $\mathrm{Cr} / \mathrm{SiO}_{2} \mathrm{Catalyst}$ for Ethylene Polymerization. ChemCatChem 2017, 9, 3364-3373. [CrossRef]

113. Cheng, R.; Liu, X.; Fang, Y.; Terano, M.; Liu, B. High-resolution 29Si CP/MAS solid state NMR spectroscopy and DFT investigation on the role of geminal and single silanols in grafting chromium species over Phillips $\mathrm{Cr} /$ silica catalyst. Appl. Catal. A: Gen. 2017, 543, 26-33. [CrossRef] 